\title{
DR. 808
}

\section{THEORY AND APPLICATION OF \\ A QUASI-EULERIAN FLUID ELEMENT \\ FOR THE STRAW CODE}

by

J. M. Kennedy and T. B. Belytschko

BASE TECHNOLOGY

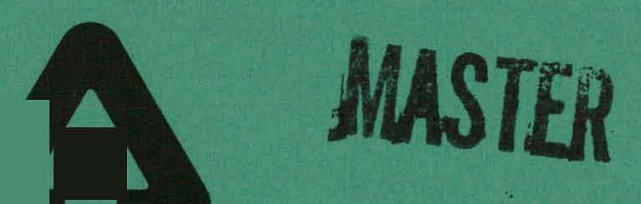

U OfC-AUA-USDOE

ARGONNE NATIONAL LABORATORY, ARGONNE, ILLINOIS

Prepared for the U. S. DEPARTMENT OF ENERGY

under Contract W-31-109-Eng-38 


\section{DISCLAIMER}

This report was prepared as an account of work sponsored by an agency of the United States Government. Neither the United States Government nor any agency Thereof, nor any of their employees, makes any warranty, express or implied, or assumes any legal liability or responsibility for the accuracy, completeness, or usefulness of any information, apparatus, product, or process disclosed, or represents that its use would not infringe privately owned rights. Reference herein to any specific commercial product, process, or service by trade name, trademark, manufacturer, or otherwise does not necessarily constitute or imply its endorsement, recommendation, or favoring by the United States Government or any agency thereof. The views and opinions of authors expressed herein do not necessarily state or reflect those of the United States Government or any agency thereof. 


\section{DISCLAIMER}

Portions of this document may be illegible in electronic image products. Images are produced from the best available original document. 
The facilities of Argonne National Laboratory are owned by the United States Government. Under the terms of a contract (W-31-109-Eng-38) between the U. S. Department of Energy, Argonne Universities Association and The University of Chicago, the University employs the staff and operates the Laboratory in accordance with policies and programs formulated, approved and reviewed by the Association.

\section{MEMBERS OF ARGONNE UNIVERSITIES ASSOCIATION}

The University of Arizona Carnegie-Mellon Univer sity Case Western Reserve University The University of Chicago University of Cincinnati Illinois Institute of Technology

University of Illinois

Indiana University

Iowa State University

The University of Iowa
Kansas State University The University of Kansas Loyola University Marquette University Michigan State University The University of Michigan University of Minnesota University of Missouri Northwestern University University of Notre Dame
The Ohio State University Ohio University

The Pennsylvania State University Purdue University Saint Louis University Southern Illinois University The University of Texas at Austin Washington Univcrsity Waync State University The University of Wisconsin

\section{NOTICE}

This report was prepared as an account of work sponsored by the United States Government. Neither the United States nor the United States Department of Energy, nor any of their employees, nor any of their contractors, subcontractors, or their employees, makes any warranty, express or implied, or assumes any legal liability or responsibility for the accuracy, completeness or usefulness of any information, apparatus, product or process disclosed, or represents that its use would not infringe privately-owned rights. Mention of commercial products, their manufacturers, or their suppliers in this publication does not imply or connote approval or disapproval of the product by Argonne National Laboratory or the U. S. Department of Energy.

Printed in the United States of America

Available from

National Technical Information Service

U. S. Department of Commerce

5285 Port Royal Road

Springfield, Virginia 22161

Price: Printed Copy $\$ 5.25$; Microfiche $\$ 3.00$ 
ARGONNE NATIONAL LABORATORY

9700 South Cass Avenue

Argonne, Illinois 60439

THEORY AND APPLICATION OF

A QUUASI-EULERIAN FLUID ELEMENT

FOR THE STRAW CODE

by

J. M. Kennedy and T. B. Belytschko*

Reactor Analysis and Safety Division

October 1978

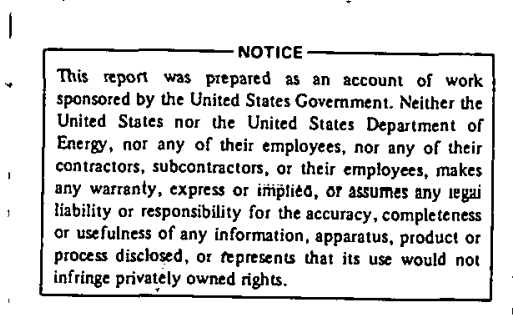

*Northwestern University 
THIS PAGE

\section{WAS INTENTIONALLY \\ LEFT BLANK}


TABLE OF CONTENTS

Page

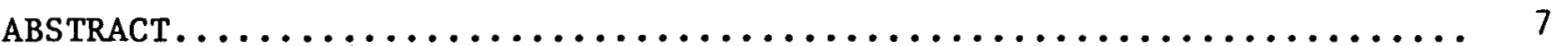

I. INTRODUCTION.............................. 7

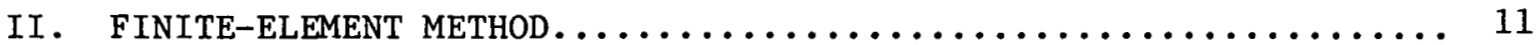

A. Quasi-Eulerian Fluid Element................... 12

B. Lagrangian Fluid Element...................... 19

C. Beam Element............................ 20

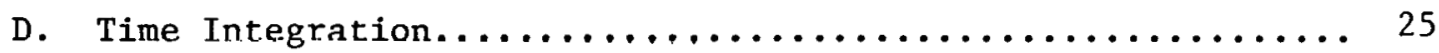

E. Artificial Viscosity........................ 26

F. Sliding Interface........................... 29

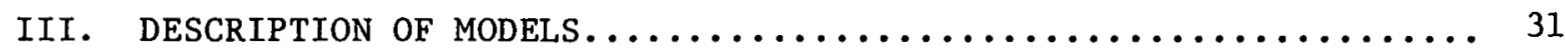

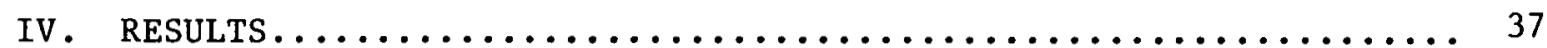

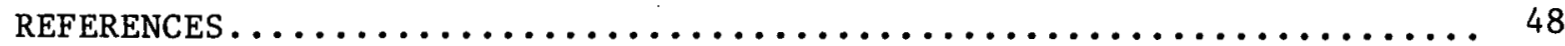


LIST OF FIGURES

No.

Title

$\underline{\text { Page }}$

1. Quadrilateral Fluid Element........................ 13

2. Subdivision of Quadrilateral into Triangles for

Evaluation of Transport Terms....................... 16

3. Beam-element Geometry and Nomenclature................. 20

4. Hourglass Type of Mesh Instability.................. 27

5. Sliding Interfaces........................... 29

6. Cross Section of Subassembly Cluster................... 31

7. Subassembly Configuration (all dimensions in $\mathrm{cm}$ ).......... 32

8. Two-dimensional Model of Subassembly Cluster

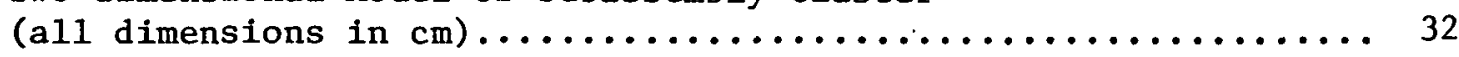

9. Three-dimensional Aspect of the STRAW 2D+ Mode1........... 33

10. Mesh Representation of Subassembly Internals.............. 35

11. One-dimensional Wave-propagation Problem................ 37

12. Pressure at $\mathrm{x}=0.5 \mathrm{~cm}$ for Lagrangian, Eulerian, and Quasi-Eulerian Descriptions..................... 38

13. Pressure at $\mathrm{x}=10.5 \mathrm{~cm}$ for Lagrangian, Eulerian, and Quasi-Eulerian Descriptions..................... 38

14. Pressure at $\mathrm{x}=0.5 \mathrm{~cm}$ for Quasi-Eulerian Description with and without Velocity Extrapolation................ 39

15. Pressure at $x=10.5 \mathrm{~cm}$ for Quasi-Eulerian Description with and without Velocity Extrapolation................ 39

16. Simplified Model of an SRI Experiment................. 39

17. SRI Experimental Model Cross Section of Subassembly Cluster..... 40

18. Pressure on Accident Subassembly................... 41

19. Pressure History in the Channel at Point $A$ of Simplified Model... 43

20. Pressure History in the Channel at Point B of Simplified Model... 43

21. Complete Model of an SRI Experiment.................. 43 


\section{LIST OF FIGURES}

No.

22. Pressure History in the Channel at Point $A$ of Complete Mode1.... 44

23. Pressure History in the Channel at Point B of Complete Model.... 44

24. Pressure History in the Channel at Point $C$ of Complete Mode1.... 44

25. Deformed Configurations of Complete Model............... 46

26. Deformed Configurations of 2D+ Subassembly Cluster Mode1...... 47

\section{LIST OF TABLES}

№.

I. Computational Procedure in Quasi-Eulerian Element.......... 18

II. Computational Procedure for Lagrangian Element............. 19

III. Computational Procedure for Beam Element................. 24

IV. Strain-Stress Values of Materials.................. 41 


\section{THIS PAGE}

\section{WAS INTENTIONALLY LEFT BLANK}


THEORY AND APPLICATION OF A QUASI-EULERIAN FLUID ELEMENT FOR THE STRAW CODE by

J. M. Kennedy and T. B. Belytschko

\begin{abstract}
Two-dimensional finite-element models for the treatment of the nonlinear, transient response of fluids and structures are described. The fluid description is quasi-Eulerian, so that the mesh can move independently of the material, and it includes a new finite-element upwinding scheme. The structural description is based on a corotational formulation in which the coordinate system is embedded in the elements, which is applicable to arbitrarily large rotations. The interface between the fluid and structure permits relative sliding, but because of the description of the quasi-Eulerian fluid, the nodes of the fluid and structure can be allowed to remain contiguous.

Modeling procedures for treating the variuus aspects of subassemblies, such as the narrow fluid channels, the fuel bundles which are immersed in the coolant, and the axial flow are developed. Calculations are made for a symetric 7-subassembly cluster and compared to experimental results. In addition, the application to a 19-subassembly cluster is described.
\end{abstract}

\title{
I. INTRODUCTION
}

The subassemblies of a reactor core are an important component in the safety system of a Liquid Metal Fast Breeder Reactor (LMFBR), Among the issues which are of concern in the safety analysis at the subassembly level are the following: (1) the structural integrity of the subassembly within which the hypothetical arcident occurs; (2) the structural integrity of adjacent subassemblies, particularly the maintenance of sufficient cross-sectional areas for the flow of the coolant; and (3) damage to the fuel pins in the adjacent subassembly, which could lead to further propagation of the accident.

The analysis of subassemblies poses several challenging problems in computer modeling. The subassemblies are separated by narrow channels of fluid, 
and since the analysis of the ultimate load capacities of subassemblies involves large motions of these channels, neither the standard Eulerian nor Lagrangian descriptions of the fluid are appropriate. Similarly, the modeling of the internals of the subassemblies, which consist of a matrix of fuel pins immersed in the coolant, has entailed the development of special techniques. Furthermore, the complex shapes of the subassemblies call for very versatile modeling techniques. In response to these needs, general finite-element methods for treating transient fluid-structure systems have been developed; ${ }^{1}$ this was the first application of finite-element methods to problems involving nonlinear, large-displacement fluid-structure interactions. The methods have since evolved considerably and, because of their generality, are applicable to a wide variety of problems in reactor safety analysis and other fields. In particular, the recently developed quasi-Eulerian elements far treating fluido in channels and other fluid-structure interfaces undergoing large displacements have considerable potential for application.

This paper describes these methods in their present stage of development. Particular emphasis has been placed on giving a comprehensive account of the finite-element treatment of the fluid, structure, and their interfaces. The treatment used for the quasi-Eulerian elements is included here and, as part of this, a new method for upwinding in finite-element methods is described. In addition, we have described the modeling procedures used in subassemblies, which will hopefully serve as a guide to modeling other systems.

Studies of the capacity of subassemblies to withstand energy releases have been underway in Great Britain, West Germany and the United States since the late 1960s. The British efforts ${ }^{2,3}$ have been primarily experimental; ful1-size models of 19- and 61-subassembly clusters have been subjected to high explosive charges detonated in a central subassembly. Charges which yielded peak pressures of $1000 \mathrm{MPa}$ with rise times of $5 \mathrm{~ms}$ and durations up to 50 ms were used.

The work in West Germany has been reported in Refs. 4 and 5. Analytical and experimental efforts have dealt primarily with the role of the fuel bundle in subassembly response and the bending behavior of the adjacent hexcan. The fuel bundle has been represented by a lattice of truss elements with resistance only in compression. Comparisons with experiments show good agreement. Also, models of channel flow have been developed which account for the coolant, using an approach similar to that in COBRA. 6 
The studies in the United States also comprise analytical and experimental efforts. The experimental efforts have focused on the response of the isolated hexcan, a hexcan surrounded by coolant, and small subassembly clusters. $^{7,8}$ Ash and Marciniak ${ }^{9,10}$ compared their analytical results with the experimental results at SRI and obtained good agreement. In addition, their work pointed out the sensitivity of the hexcan response to the degree of corner work-hardening.

The major analytical tools which have been developed for structural safety studies of subassemblies at Argonne National Laboratory are the computer programs STRAW, 1,11 SADCAT, 12,13 and REXCAT.14 STRAW, which is the topic of this paper, is a two-dimensional, nonlinear, finite-element program with fluid elements and structural elements which are used to represent subassembly walls, coolant channels, and internals. The program is used to model cross sections of the subassembly geometry normal to the axis of the subassemblies and fuel pins. The three-dimensfonal effects, such as the axial flow of the coolant and the axial bending resistance of the adjacent subassemblies, are treated by coupling one-dimensional models of the axial flow and the flexural resistance to the two-dimensional models. This approach entails assumptions about the phenomenology of the accident, but as a consequence yields significant simplifications and economy of computation. Therefore, configurations involving both the accident hexcan and one to three layers of adjacent hexcans can be treated by STRAW. SADCAT, on the other hand, is a three-dimensional plate-shell program which can model the actual geometry of the subassemblies without any geometrical simplifications. In REXCAT, SADCAT is coupled with the two-dimensional Lagrangian finite-difference program REXCO-HT. ${ }^{15}$ Thus, the internals of the hexcan, including both the energy source and the hydrodynamics, are modeled as axisymmetric, whereas the hexcan walls are treated as three-dimensional.

The three-dimensional analysis methods are still too expensive for use in elaborate parameter studies or models which include hexcans adjacent to the accident hexcan. Thus, in the field of subassembly safety analysis, as in many other computer modeling fields, while three-dimensional analyses are feasible and not difficult in principle, computational cost has severely limited their use and development. 
In this paper, we will confine ourselves to the two-dimensional methods and models, which are implemented in the STRAW program. The next section presents the finite-element method developed for this program. The modeling procedure for the subassemblies is described in Sec. III. Section IV gives some sample results and illustrates some of the fluid-structure effects found in the problem of subassembly response. 


\section{FINITE-ELEMENT METHOD}

The computational methods for the subassemblies and their internals must be capable of treating structures of complex shape and their interaction with the fluid in which they are embedded. Consequently, these methods must be able to treat almost arbitrary combinations of fluid and structural geometries. Furthermore, the structures must be treated by bending theory if the total number of degress of freedom is to be kept to a reasonable limit. For example, if flexural theory is used, the deformation at each point of the structural cross section is defined by a single node with three degrees of freedom. By contrast, a continuum description of the structures would entail about 5 nodes at each cross section, two degrees of freedom at each node, and thus a total of 10 degrees of freedom, at each section. Thus, the.use of a flexural theory for the structural elements is imperative for an economic solution.

The finite-element method is ideally suited for mixing fluid elements with structural elements. In the finite-element method, in both the structural and fluid portions, the discrete equations of the mesh are written in the form

$$
M_{K L} \ddot{u}_{i L}+F_{i K}^{i n t}-F_{i K}^{e x t}=0 \text {, }
$$

where

$$
\begin{aligned}
& \mathrm{M}_{\mathrm{KL}}= \text { global mass matrix (composed of lumped mass entries); } \\
& \mathrm{u}_{\mathrm{iL}}= \text { displacements of the nodes; superscript dots denote time deriva- } \\
& \text { tives, so that } \ddot{\mathrm{i}}_{\mathrm{iL}} \text { are the accelerations; } \\
& \mathrm{F}_{\mathrm{iK}}^{\mathrm{int}=} \text { the nodal forces resulting from the response of the structure and } \\
& \quad \text { fluid; } \\
& \mathrm{F}_{\mathrm{iK}}^{\text {ext }=} \text { the nodal forces corresponding to externally applied loads. } \\
& \text { The upper-case subscripts refer to nodes, the lower-case subscripts to }
\end{aligned}
$$
degrees of freedom at a node. Each fluid node in these two-dimensional models has two degrees of frccdom: translations in the $x$ and $y$ directions, whereas each structural node has three degrees of freedom: translations in the $x$ and $y$ directions and rotation of the cross section. We will use numerical subscripts and component subscripts interchangeably; thus $u_{1} \equiv u_{x}$ and $u_{2} \equiv u_{y}$. In addition, we will sometimes denote coordinates by $x_{1}$; at other times we will simply use $x$ and $y$, su that $\left(x_{1}\right.$ and $\left.x\right)$ and $\left(x_{2}\right.$ and $\left.y\right)$ are interchangeable. 
The most important ingredient in the fintte-element procedure is the calculation of the internal nodal forces which arise from the resistance of the structure and fluid. These are given by (see, for example, Belytschko and Kennedy ${ }^{16}$ )

$$
F_{i K}^{i n t}=\sum_{e} L_{I K}^{(e)} \mathrm{f}_{i I}^{(e) i n t},
$$

where superscript e refers to the element number, $\mathrm{L}_{\mathrm{IK}}$ is the connectivity matrix, and $f_{i I}^{i n t}$ are the element nodal forces. The element nodal forces are defined by

$$
\dot{u}_{i I} f_{i I}^{(e) i n t}=\dot{E}+\dot{u}_{i I} t_{i I}^{(e)}
$$

for arbitrary $\dot{u}_{1 .}$. Here $E$ is the internal energy of the element and $t_{i I}^{(e)}$ are any momentum-transport terms which may occur; for Lagrangian elements the transport terms vanish. Equation (3) is the means through which the internal nodal forces for an element may be derived for a fluid or structural element once the velocity field in the element is assumed. Derivations for several of the key elements used in these models are given below. Equation (2) represents the summation of the element nodal forces $f(e)$ int into the total internal nodal forces. Although Eq. (2) represents this process as a matrix multiplication, in fact $\mathrm{L}_{\mathrm{IK}}^{(\mathrm{e})}$ is a Boolean matrix, and in the computer program the total internal forces are obtained by simply summing the element nodal internal forces according to the element global node numbers.

The three major elements in the STRAW program are the (1) quasi-Eulerian fluid element, (2) the Lagrangian fluid element, and (3) the beam element. The derivation of the nodal-force equations and the computational proredires for each of these elements is given in the following.

\section{A. Quasi-Eulerian Fluid Element}

The quasi-Eulerian fluid element is an element for which the motion of the nodes may differ from the motion of the material, in this case, the fluid. We will designate the material velocity by $\dot{u}^{M}$, the mesh (or grid) velocity by $\dot{u}^{G}$. When $\dot{u}^{M}=\dot{u}^{G}$, the element is Lagrangian and all nodes move with the material velocity. When $\dot{u}^{G}=0$, the element nodes are fixed in space and the elements are Eulerian. The element is called quasi-Eulerian because whenever $\dot{u}^{M} \neq \dot{u}^{G}$ the transport terms appear in the momentum equation, so that the 
treatment is very similar to that in Eulerian descriptions. We will consider only inviscid, compressible flow. Both quadrilateral and triangular elements are included.

Quasi-Eulerian treatments have been previously developed by Noh, 17 Trulio, ${ }^{18}$ and Hirt et al.,$^{19}$ in finite-difference formats. Often these methods are called Arbitrary Lagrangian Eulerian (ALE). Donea et al., 20 have reported a finite-element quasi-Eulerian method.

We will now develop the internal nodal forces for this element; in the following we will drop the superscripts on $f_{i I}$ and use the convention that lower-case nodal forces pertain to an element. In this development, we will concentrate on the quadrilateral element and only outline the triangular element. This corresponds to the relative importance of the elements; the quadrilateral is used in most of the meshes, while the triangle is used only for the edges or irregular shapes.

The quadrilateral element is shown in Fig. 1. Since we consider only

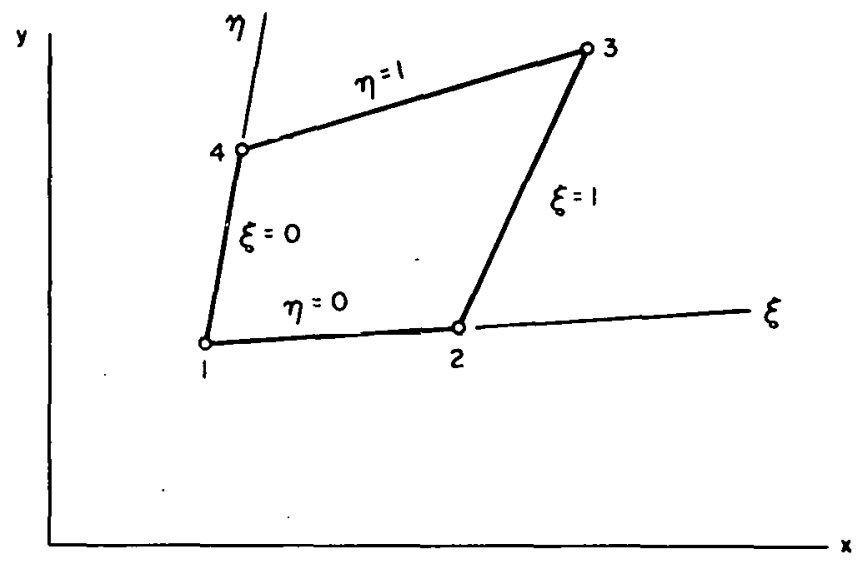

Fig. 1. Quadrilateral Fluid Element.

(ANL Neg. No. 900-78-15.)

adiabatic process, the rate of change of internal energy of the element is given by

$$
\dot{E}=-\int_{V} \frac{\partial \dot{u}_{i}}{\partial x_{i}} d V,
$$

where $p$ is the pressure and $V$ the volume of the element. The velocity field in the element is approximated by the standard quadrilateral shape functions (see Zienklewlcz ${ }^{21}$ for delails): 


$$
u_{i}\left(x_{j}\right)=u_{i I} \phi_{I}(\xi, n),
$$

where a repeated subscript implies a summation over the appropriate range; in this case, since the repeated subscript I refers to the nodes of the element, the range is the number of nodes for this element, which is 4 . This velocity field applies both to the material and grid velocitles.

The shape functions for the quadrilateral are

$$
\begin{array}{ll}
\phi_{1}=(1-\xi)(1-n) ; \phi_{3}=\xi n ; \\
\phi_{2}=\xi(1-n) ; & \phi_{4}=(1-\xi) n,
\end{array}
$$

where $\xi$ and $n$ are defined by the isoparametric transformation

$$
\mathrm{x}_{i}=\mathrm{x}_{\mathrm{i} T \mathrm{~T}} \phi_{\mathrm{T}}(\zeta, n) \text {, }
$$

so that derivatives are given by (see Ref. 21)

$$
\begin{aligned}
& \frac{\partial()}{\partial x}=\frac{1}{j}\left(\frac{\partial y}{\partial n} \frac{\partial()}{\partial \xi}-\frac{\partial y}{\partial \xi} \frac{\partial()}{\partial \eta}\right) ; \\
& \frac{\partial()}{\partial y}=\frac{1}{j}\left(\frac{\partial x}{\partial \xi} \frac{\partial()}{\partial \eta}-\frac{\partial x}{\partial \eta} \frac{\partial()}{\partial \xi}\right)
\end{aligned}
$$

where $j$ is the Jacobian

$$
j=\frac{\partial x}{\partial \xi} \frac{\partial y}{\partial \eta}-\frac{\partial x}{\partial \eta} \frac{\partial y}{\partial \xi} \text {. }
$$

For an inviscid fluid, the pressure is given by the equation of state

$$
p=p(p, T) \text {, }
$$

where $\rho$ is the density and 'I' the temperature. We will assume that $\rho$, and hence $p$, are constant within the element. This is not consistent with the rate of dilation (volumetric strain rate) associated with the velocity field in this element, because an evaluation of the volumetric strain rate by substituting the velocity field, Eqs. (6), into Eq. (8), shows that the volumetric strain rate is not constant in the element. However, it is not fully linear, and taking into account this variation would entail a numerical quadrature with a minimum of four points rather than the simple formulas that will be given here. This would raise computational effort per element by a factor of 3 to 4 ; it is our opinion that using more elements is more cost-effective than taking into account the small variations in pressure by a 4-point quadrature. 
To obtain the nodal forces, we will need the identity

$$
\mathrm{J} \frac{\partial \dot{\mathrm{u}}_{i}}{\partial \mathrm{x}_{i}}=\dot{\mathrm{J}}
$$

where $\mathrm{J}$ is the Jacobian of the transformation between the current volume $\mathrm{V}$ and the original volume $\mathrm{V}_{\mathrm{o}}$. Combining Eq. (11) with Eq. (4), we obtain

$$
\dot{\mathrm{E}}=-\mathrm{p} \int_{V} \frac{1}{\mathrm{~J}} \dot{\mathrm{J}} \mathrm{dV}=-\mathrm{p} \int_{V_{0}} \dot{\mathrm{J} d V_{0}}=-\mathrm{p} \dot{\mathrm{V}}
$$

Simple geometry can be used to show that the volume rate is

$$
\dot{\mathrm{V}}=\mathrm{B}_{\mathrm{iI}} \dot{\mathrm{u}}_{\mathrm{iI}},
$$

where

$$
\begin{aligned}
& \mathrm{B}_{1 \mathrm{I}}=\frac{1}{2} \mathrm{y}_{\mathrm{JL}} ; \\
& \mathrm{B}_{2 \mathrm{I}}=\frac{1}{2} \mathrm{x}_{\mathrm{LJ}} ; \\
& \mathrm{y}_{\mathrm{JL}}=\mathrm{y}_{\mathrm{J}}-\mathrm{y}_{\mathrm{L}} ; \mathrm{x}_{\mathrm{LJ}}=\mathrm{x}_{\mathrm{L}}-\mathrm{x}_{\mathrm{J}},
\end{aligned}
$$

and it is assumed that $\mathrm{J}$ is one node counterclockwise from $\mathrm{I}$; $\mathrm{K}$ two nodes counterclockwise from I; etc.

Combining Eqs. (12) and (13) with Eq. (3) in the absence of transport, we obtain

$$
\dot{\mathrm{u}}_{i \mathrm{I}} \mathrm{f}_{i I}=-\mathrm{pB}_{i I} \dot{\mathrm{u}}_{\mathrm{iI}}
$$

Since the above, which represents consistency in energy between the nodal variables and the element variable, must hold for arbitrary $\dot{u}_{i I}$, it follows that

$$
\mathrm{F}_{\mathrm{iI}}=-\mathrm{PB}_{\mathrm{iI}}
$$

To evaluate the discrete transport terms $t_{i I}$, we will use a Galerkin approach. It has been documented 22,23 that straight Galerkin approaches to the transport terms when used with piecewise linear velocity fields yield oscillatory solutions. This has also been noted in the finite-difference literaturc (cee Roach ${ }^{24}$ ), where sperial upwind differencing forms have been developed. In Refs. 22 and 23, finite-element versions of upwind transport 
discretizations were obtained by using higher-order weight functions skewed in the upwind direction. This type of "upwinding" makes numerical integration necessary. In the STRAW program, a simpler upwinding scheme has been incorporated, and it will be described here.

The Galerkin approximation to the transport term gives

$$
\begin{aligned}
& t_{i I}^{*}=\int_{V} \rho \phi_{I} \frac{\partial \dot{u}_{i}^{M}}{\partial x_{j}} \cdot \dot{u}_{j}^{D} d V ; \\
& \dot{u}_{j}^{D}=\dot{u}_{j}^{M}-\dot{u}_{j}^{G},
\end{aligned}
$$

where the asterisk designates that this transport term will be modified to account for upwinding before use in Eq. (16). This is arromplished by

$$
t_{i I}=t_{i I}^{*}\left(1+\gamma_{I}\right)
$$

where

$$
\gamma_{I}=\frac{\overline{\mathrm{AD}}}{\gamma} \int_{V} \frac{\partial \phi}{\partial \mathrm{x}_{i}} \dot{\mathrm{u}}_{i}^{\mathrm{D}} \mathrm{dV},
$$

$\gamma$ is a scale factor chosen, so that $\left|\gamma_{I}\right|<1$, and $\overline{\mathrm{AD}}$ is the donor-cel1 fartnr, si that

$$
\begin{aligned}
& \overline{\mathrm{AD}}=1 . \Rightarrow f_{1111} \text { upwinding; } \\
& \overline{\mathrm{AD}}=0 \Rightarrow \text { no upwinding. }
\end{aligned}
$$

In order to avoid numerical integration for the evaluation of the transport terms, they were evaluater hy subdividing the quadrilateral intu Lidugles in two ways, as shown in Fig. 2. For each triangle, the shape functions $\phi_{I}$ are the triangular coordinates $\xi_{\mathrm{I}}$, so that
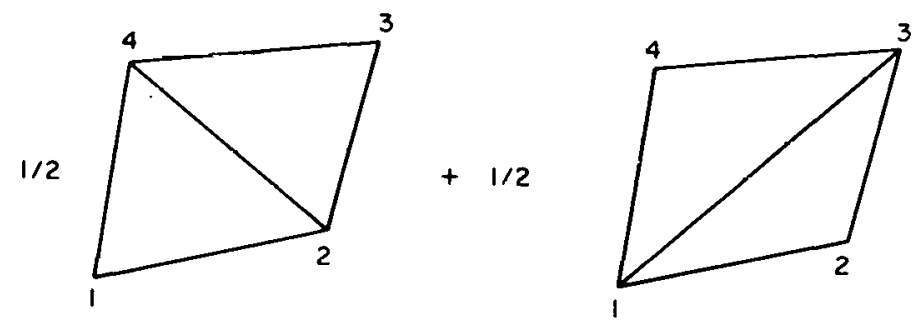

Fig. 2. Subdivision of Quadrilateral into Triangles for Evaluation of Transport Terms. (ANL Neg. No. 900-78-16.) 


$$
t_{i I}^{*}=\dot{u}_{i J}^{M} \dot{u}_{j K}^{D} \int_{A} \rho \zeta_{I} \zeta_{K} \frac{\partial \zeta_{J}}{\partial x_{j}} d A .
$$

Evaluation of the integral yields

$$
t_{i I}=\frac{1}{24} \dot{u}_{i J}^{M} \dot{u}_{j K}^{D} \ell_{j J}\left(I_{I K}+\delta_{I K}\right)
$$

where

$$
\ell_{1 J}=y_{K}-y_{L} ; \ell_{2 J}=x_{L}-x_{K}
$$

for a triangle with nodes $\mathrm{J}, \mathrm{K}$, and $\mathrm{L}$ in counterclockwise order; the matrix $\mathrm{I}_{\mathrm{IK}}$ is given by

$$
I_{I K}=1 \text { for all } I, K \text {, }
$$

and $\delta_{I K}$ is the usual Kronecker delta (unit matrix)

$$
\delta_{I K}=\left\{\begin{array}{l}
0 \text { if } I \neq K \\
1 \text { if } I=K .
\end{array}\right.
$$

The evaluation of Eq. (19) yields

$$
\begin{aligned}
\gamma_{I} & =\frac{\overline{A D}}{\gamma} \dot{u}_{i J}^{D} \int_{A}^{\frac{\partial \zeta_{I}}{\partial x_{i}} \zeta_{j} d A} \\
& =\frac{\overline{A D}}{6 \gamma} \ell_{i I}\left(\dot{u}_{i 1}^{D}+\dot{u}_{i 2}^{D}+\dot{u}_{i 3}^{D}\right) .
\end{aligned}
$$

The transport terms for the four triangular elements are assembled in the standard manner according to the node numbers and then halved to account for the two layers of triangular elements.

In updating the density of the element, the integral form of the conservation of mass is used, which gives

$$
\frac{d}{d t} \int_{V} \rho d V=\int_{S} \rho u_{i} n_{i} d s,
$$

where $\mathrm{n}_{i}$ is a unit normal to the surface $S$. The assumption of constant density in the element and evaluation of the right-hand integral with the shape functions, Eqs. (6), yield 


$$
\begin{aligned}
& \frac{d^{*} \rho}{d t}=\frac{\rho}{2 A} \sum_{\substack{I=1 \\
J=I+1}}^{4}\left[y_{J I}\left(\dot{u}_{x I}^{D}+\dot{u}_{x J}^{D}\right)+x_{J I}\left(\dot{u}_{y I}^{D}+\dot{u}_{y J}^{D}\right)\right] ; \\
& \frac{d \rho}{d t}=\frac{d^{*} \rho}{d t}-\rho B_{i I} \dot{u}_{i I}^{G} .
\end{aligned}
$$

We have here used an asterisk on the derivative to indicate that the derivative is neither a material nor spatial derivative; as the volume $\mathrm{V}$ moves through space, the velocity of its surface points may differ from the material velocities of these points, so $d^{*} \rho / d t$ represents the rate of change of $p$ along this arbitrary path in space-time.

The procedure used in the computer program is given in Table $I$. The procedure 1s typical of that used for elements in an explicit time-integration finite-element program. The only difference is that the element must know which elements are adjacent to it to compute Eqs. (26) and (27); for these purposes, an adjacency table is constructed which lists the element that border each of the sides; if no element borders a given side, a zero is entered for that side.

Table I. Computationa1 Procedure in Quasi-Eulerian Element

1. Modify element nodal velocities (both material and grid) by forward extrapolation of Eq. (54).

2. Compute new density of element by Eq. (27) and $\rho^{\text {new }}=\rho^{\text {old }}+\Delta t \frac{d p}{d t}$.

3. Modify masses of nodes connected to element according to $\frac{d^{*} \rho}{d t}$.

4. Use equation of state $p(\rho, T)$ to find new pressure.

5. Compute linear artificial viscosity, Eq. (55).

6. Compute nodal forces due to pressure (from equation of state and artificial viscosity by Eq. (16).

7. Compute transport terms $t_{i I}$ by Eqs. (17) and (19), and add to nodal forces $\mathrm{f}_{\mathrm{iI}}$.

8. Compute nodal forces due to hourglass viscosities using Eqs. (61-63), and add to nodal forces $f_{i I}$.

9. Store current pressure, density, and other element variables.

10. Add internal nodal forces $\mathrm{f}_{\text {iI }}$ into total internal nodal force array $\mathrm{F}_{\mathrm{iI}}^{\mathrm{int}}$. 
The treatment of the triangular element is quite similar and has already been alluded to in the development of the transport terms. For the triangle the shape functions are the triangular coordinates, so that

$$
\phi_{I}(x, y)=\zeta_{I} .
$$

These shape functions are linear in $x$ and $y$, and the rate of volumetric strain is constant within the element; thus, unlike for the quadrilateral, a constant density and pressure is consistent with the kinematics of the element. Hence, Eq. (12) follows exactly. Through some elementary geometry, the volume rate can be expressed in the same form as Eq. (13), with

$$
\begin{aligned}
& \mathrm{B}_{1 \mathrm{I}}=\frac{1}{2} \mathrm{y}_{\mathrm{JK}} ; \\
& \mathrm{B}_{2 \mathrm{I}}=\frac{1}{2} \mathrm{x}_{\mathrm{KJ}} .
\end{aligned}
$$

Equations (16), (21), and (24) then give all relations for the triangle.

\section{B. Lagrangian Fluid Element}

The Lagrangian fluid element is a special case of the quasi-Eulerian fluid element with $\dot{u}^{M}=\dot{u}$. The transport terms thus vanish.

The STRAW program includes quadrilateral, triangular, and pentagonal elements, but quadrilateral elements are recommended for most meshing. The computational procedure for Lagrangian elements is outlined in Table II.

Table II. Computational Procedure for Lagrangian Element

1. Compute new density by $\frac{d \rho}{d t}=-\rho B_{i I} \dot{u}_{i I} ; \rho^{\text {new }}=\rho^{o l d}+\Delta t \frac{d \rho}{d t}$.

2. Use equation of state $p(\rho, T)$ to find new pressure.

3. Compute linear artificial viscosity, Eq. (55).

4. Compute nodal forces by Eq. (16).

5. Compute nodal forces, due to antihourglass, by Eq. (61-63) and add to element nodal forces.

6. Store current pressure, density, and other element variables.

7. Add internal nodal forces $f_{i I}$ into total internal nodal force array $F_{i I}^{i n t}$. 


\section{Beam Element}

The beam element is illustrated in Fig. 3. Each beam element has two actual nodes, but unlike the fluid elements, it has three degrees of freedom per node, so that the nodal displacements at any node are

$$
u_{i I}=\left\{\begin{array}{c}
u_{x I} \\
u_{y I} \\
\theta_{I}
\end{array}\right\} \text {, }
$$

where $\theta_{I}$ is the rotation in radians. The corresponding nodal forces are

$$
f_{i I}=\left\{\begin{array}{c}
f_{x I} \\
f_{y I} \\
m_{I}
\end{array}\right\} \text {, }
$$

where $m_{I}$ is a moment.
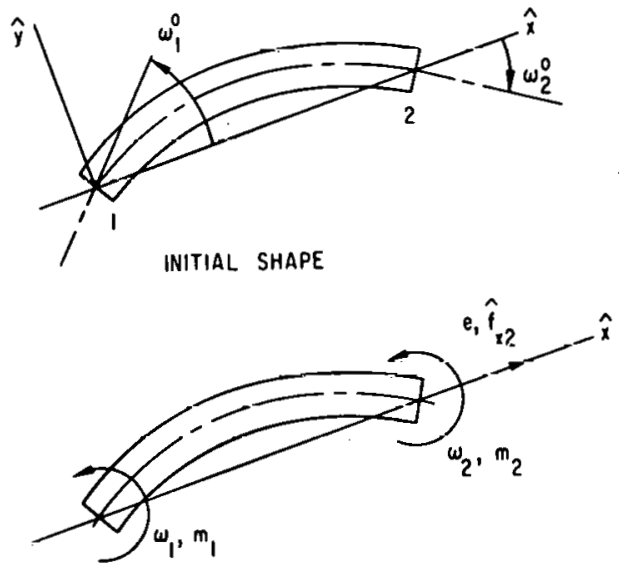

DEFORMATION NODAL DISPLACEMENTS AND FORCES

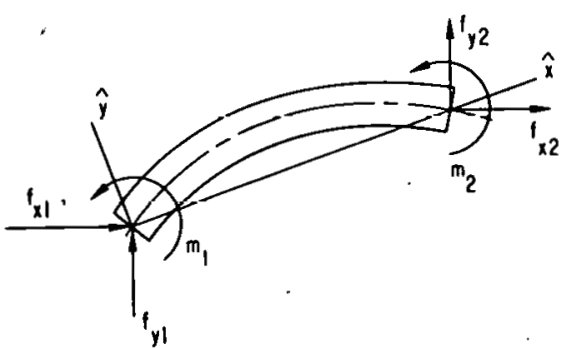

NODAL DISPLACEMENTS AND FORCES

Fig. 3. Beam-element Geometry and Nomenclature. (ANL Neg. No. 900-78-1, Rev. 1.) 
An important aspect of this beam element is the use of a corotational formulation which permits the treatment of arbitrarlly large rotations of the element. The essential feature of a corotational formulation is that a coordinate system $(\hat{x}, \hat{y})$ is embedded in each element so that it rotates with the element. In this beam element, the corotational system is embedded so that $\mathbf{x}$ always connects the two nodes of the beam. Corotational formulations have been extensively described by Belytschko and Hsieh.25,26 In these papers the corotational formulations were limited to elements which were initially straight and wherein the rotation of any part of the element relative to the corotational coordinate was small. Since then, Belytschko and Glaum ${ }^{27}$ have developed formulations which account for initlal curvature and moderate relative rotations, and these have been incorporated here. However, all of these formulations are limited to moderately small strains, of the order of about $10 \%$.

These formulations are applicable to arbitrary nonlinear materials. Although most of our work has been limited to elastic-plastic materials, as long as an increment stress can be programmed as an increment of strain and previous stress and strain, it is easily incorporated in the program.

These elements are based on the standard Euler-Bernoulli assumptions that the deformation is characterized by the deformation of the midline of the beam, and that all straight lines normal to the midline remain straight and normal. Shear corrections terms are not included.

An important aspect of the formulation used here and in Refs. 25-27 is that, on the element leve1, only those degrees of freedom associated with deformation of the element are considered. This concept was introduced by Argyris et al. ${ }^{28}$ It saves considerable computational effort, and, in addition, in transient problems it enhances the stability of the computational procedure, for it insures the conservation of energy on an element level. 25

The deformation displacements and the corresponding deformation nodal forces for this element are

$$
\begin{aligned}
& \hat{u}^{\text {def }}=\left(e, w_{1}, w_{2}\right) ; \\
& \hat{f}^{\text {def }}=\left(\hat{f}_{x 2}, m_{1}, m_{2}\right),
\end{aligned}
$$

ẉhere 


$$
\begin{aligned}
& \text { e } \quad \text { elongation of the element; } \\
& { }_{I}^{\omega_{I}}=\theta_{I}-\theta^{\text {rig }} ; \\
& \theta^{\text {rig }}=\text { rigid body rotation of the element. }
\end{aligned}
$$

The elongation and rigid-body rotation are respectively given by

$$
e=\frac{1}{2 l}\left(2 x_{i J I} u_{i J I}+u_{i J I} u_{i J I}\right)
$$

(sum on $i$ only)

and

$$
\sin \theta^{\mathrm{rig}}=\frac{1}{\ell^{2}}\left(\mathrm{u}_{\mathrm{yJI}} \mathrm{x}_{J I}-\mathrm{u}_{\mathrm{xJI}} \mathrm{y}_{J I}\right) .
$$

The displacement fields associated with the deformation displacements are

$$
\begin{aligned}
& \hat{u}_{y}^{\operatorname{def}} \hat{(x)}=\omega_{1} \phi_{I}(\hat{x}) ; \\
& \phi_{1}(\hat{x})=\xi^{3}-2 \xi^{2}+\xi ; \\
& \phi_{2}(\hat{x})=\xi^{3}-\xi^{2} ; \\
& \hat{u}_{x}^{\operatorname{def}}=e \xi ; \\
& \xi=\hat{x} / \ell .
\end{aligned}
$$

It should be noted that, because of the way the rigid body rotation is eliminated, the $\hat{y}$ component of the displacement vanished at both endpoints, i.e., nodes, of the element.

If the beam is initially curved, its shape is specified by initial displacement $\hat{u}_{y o}$ of the midline from the $\hat{x}$ axis in the form

$$
\hat{u}_{y o}(\hat{x})=\omega_{I}^{o} \phi_{I}(x),
$$

where $\omega_{I_{\Lambda}}^{o}(I=1$ and 2$)$ are the initial angles between the midline of the beam and the $x$ axis.

The strain displacement equations for the beam element are

$$
\hat{\varepsilon}_{x}=\frac{\partial \hat{u}_{x}^{\text {def }}}{\partial \hat{x}}+\frac{1}{2} \omega^{2}+\omega^{\circ} \omega-\hat{y} \frac{\partial^{2} \hat{u} \hat{u}^{\text {def }}}{\partial \hat{x}^{2}} .
$$


This strain, as shown in Ref. 27 , is valid for moderate values of $\omega_{0}$ and $\omega$ (about 0.1). It corresponds to the stretch tensor, or engineering strain.

The rale of internal work is given by

$$
\dot{E}=\int_{V}^{\dot{i}} \hat{\varepsilon_{X}} \hat{\sigma d V},
$$

where $\hat{\sigma}$ is the conjugate corotational stress. The nodal forces, can now be. obtained through Eq. (3). Taking the rate of strain from Eq. (39), substituting in the shape functions, then substituting into Eq. (40), and using Eq. (3) and the arbitrariness of the deformation nodal velocities, we obtain

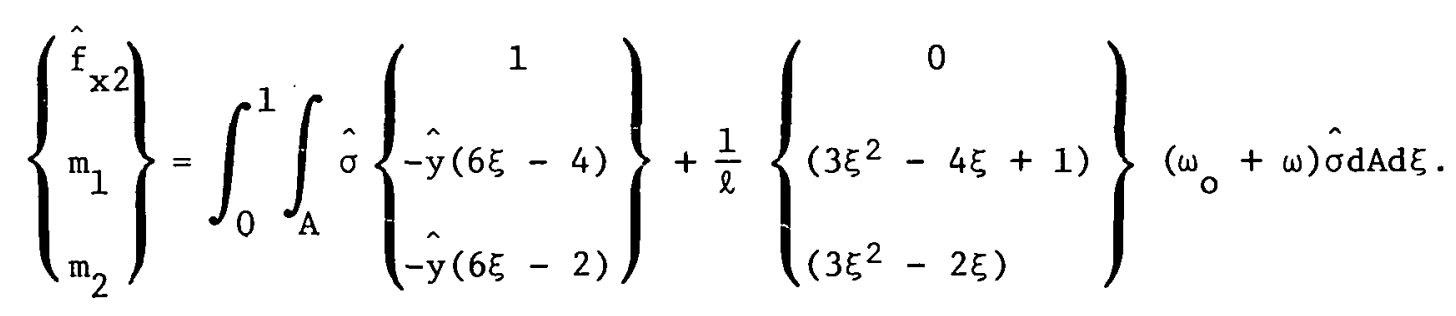

It is then assumed that $\hat{\sigma}$ varies linearly in $\hat{x}$, which is the actual situation whenever the material is linear, for that is how the strain $\hat{\varepsilon}$ varies.

The following quantities are evaluated numerically:

$$
\mathrm{p}_{\mathrm{I}}=\int_{\mathbf{A}} \hat{\sigma} \mathrm{dA}
$$

and

$$
m_{1}=\int_{\mathrm{A}} \hat{\mathrm{y}} \hat{\sigma} \mathrm{dA},
$$

where $I=1$ and 2 correspond to the two nodes, that is, $\xi=0$ and $\xi=1$, respectively. The integrals in Eqs. (42) and (43) are evaluated numerically by trapezoidal formulas. Since $\hat{\sigma}$ is assumed to vary linearly in $\hat{x}$, it follows that $\mathrm{p}(\xi)$ and $m(\xi)$ also vary linearly in $\hat{\mathrm{x}}$, so that

$$
\begin{aligned}
& \mathrm{p}(\xi)=\left(\mathrm{p}_{2}-\mathrm{p}_{1}\right) \xi+\mathrm{p}_{1} ; \\
& m(\xi)=\left(m_{2}-m_{1}\right) \xi+m_{1} .
\end{aligned}
$$

Equation (41) may then be integrated to yield 


$$
\left\{\begin{array}{l}
\hat{\mathrm{F}}_{\mathrm{x} 2} \\
\mathrm{~m}_{1} \\
\mathrm{~m}_{2}
\end{array}\right\}=\left\{\begin{array}{c}
\frac{1}{2}\left(\mathrm{p}_{1}+\mathrm{p}_{2}\right) \\
m_{1} \\
m_{2}
\end{array}\right\}+\frac{\ell}{60}\left\{\begin{array}{c}
0 \\
\mathrm{p}_{1}\left(6 \bar{\omega}_{1}-\bar{\omega}_{2}\right)+\mathrm{p}_{2}\left(2 \bar{\omega}_{1}-\bar{\omega}_{2}\right) \\
\mathrm{p}_{1}\left(-\bar{\omega}_{1}+\bar{\omega}_{2}\right)+\mathrm{p}_{2}\left(-\bar{\omega}_{1}+6 \bar{\omega}_{2}\right)
\end{array}\right\}
$$

where

$$
\bar{\omega}=\omega^{0}+\omega .
$$

The last term in Eq. (45) becomes significant only when $\bar{w}$, the sum of initial rotation and deformation relative rotations, are moderately large $(0.01$ to $0.1)$. It has been found that generally these terms are significant only in a few elements of the mesh, in which case the computation of all terms associated with these quantities can be suppressed wherever the terms $\omega_{I}$ and $\omega_{I}^{0}$ are small. The complete set of element nodal forces are obtained from the deformation nodal forces by equilibrium, which gives

$$
\begin{aligned}
& \hat{\mathrm{f}}_{\mathrm{x} 1}=-\hat{\mathrm{f}}_{\mathrm{x} 2} ; \\
& \hat{\mathrm{f}}_{\mathrm{y} 1}=-\hat{\mathrm{f}}_{\mathrm{y} 2}=\frac{\mathrm{m}_{1}+\mathrm{m}_{2}}{\ell} .
\end{aligned}
$$

These forces are then transformed to components in the global coordinate system. The sequences of computations is shown in Table III.

\section{Table III. Computational Procedure for Beam Element}

1. Compute element deformation displacements through Eq. (32-34).

2. At each end of the element:

i. Cumpute strains at all points through thickness by Eq. (39).

ii. Compute new stress by stress-strain law.

iii. Compute $\mathrm{p}_{\mathrm{I}}$ and $m_{\mathrm{I}}$ by numerical integration.

3. Compute deformation nodal forces by Eq. (45).

4. Compute axial artifical viscosity nodal force by Eq. (57) and add to deformation nodal forces.

5. Store current stress and strains.

6. Find all nodal forces in corotational components by Eq. (46).

7. Transform nodal forces to global components.

8. Add element nodal forces into total nodal force array $F_{i I}^{\text {int }}$. 


\section{Time Integration}

Time integration is carried out by the central-difference explicit method. For the central-difference method, the velocities and displacements are updated by the formulas

$$
\underline{\dot{u}}(t+1 / 2 \Delta t)=\underline{\dot{u}}(t-1 / 2 \Delta t)+\Delta t \underline{u}(t)
$$

and

$$
\underline{u}(t+\Delta t)=\underline{u}(t)+\Delta t \underline{\dot{u}}(t+1 / 2 \Delta t),
$$

where superscript dots denote time derivatives and $\Delta t$ is the time step. For purposes of numerical stability the time step is limited by

$$
\Delta t \leq \frac{2}{\omega_{\max }}\left(\sqrt{1+\mu^{2}}-\mu\right),
$$

where $\omega_{\max }$ is the maximum eigenvalue (the highest frequency squared) of the system and $\mu$ is the fraction of critical damping in the highest frequency.

For constant-strain elements, such as the Lagrangian hydrodynamic elements and the membrane forces in the beam, the highest frequency may be estimated by the formula

$$
\omega_{\max }=\frac{2 l}{\ell},
$$

where $c$ is the maximum elastic or the acoustic-wave speed in the material and $\ell$ the minimum element dimension. For beam elements, the frequency of the bending mode may be estimated by

$$
\omega_{\max }=\frac{12 \mathrm{cr} G}{\ell^{2}},
$$

where $\mathrm{r}_{\mathrm{G}}$ is the radius of gyration of the cross section. Since both Eqs. (50) and (51) govern the behavior of a beam, the time step in a beam mesh is governed by whichever of these frequencies is larger. Thus Eq. (45) governs for a beam as long as

$$
\ell \leq 6 \mathrm{r}_{\mathrm{g}} \text {. }
$$

For a uniform cross section, the radius of gyration is given by $r_{g}^{2}=h^{2} / 12$, where $\mathrm{h}$ is the thickness of the beam, so Eq. (52) becomes

$$
\ell \geq \sqrt{3} \mathrm{~h} .
$$


It is important to keep beam elements long enough so that Eq. (53) is not violated by much, for otherwise Eq. (51) governs and $\Delta t$ decreases with the square of element length.

For the quasi-Eulerian elements, an additional constraint is imposed by the requirement that a material point cannot traverse an element within a time step. 19 An additional aspect of the quasi-Eulerian elements is that a forward extrapolation of the velocities, as proposed by Donea et a1. , 20 has been used. Thus, in the subroutine for the quasi-Eulerian elements, before any computations are made the velocities are extrapolated by

$$
\dot{u}_{i I}(t)=\dot{u}_{i I}(t-1 / 2 \Delta t)+1 / 2 \Delta t \ddot{u}_{i I}(t-\Delta t),
$$

so that the transport terms in Eq. (3) are for time $t$ like the rest of the terms. It is interesting to note that Donea et al. used this extrapolation in conjunction with the Newmark $\beta$-method, where it is necessary even to correctly evaluate the change in density from the velocities. However, as shown in the results, this extrapolation also has significant effects with the centraldifference method.

\section{E. Artificial Viscosity}

In the integration of the finite-element equations of motion with small time steps, such as is generally the case in explicit integration, highfrequency oscillations which are called "spurious oscillations" or "aliasing" will appear in an updamped system. The severity of these oscillations tends to increase if the mesh is rather heterogeneous. These oscillations can be reduced and sometimes eliminated by the use of a suitable artificial viscosity, which is really a numerical damping.

In Ref. 29, Belytschko et al. have shown that a viscous stress given by

$$
\dot{\sigma}_{i j}^{v i s}=\mu \rho \sqrt{A}\left[\left(c_{L}-c_{S}\right) \dot{\varepsilon}_{\ell \ell} \delta_{i j}+2 c_{S} \dot{\varepsilon}_{i j}\right]
$$

damps the highest mode of an elastic, isotropic element by a fraction of critical damping, $\mu$. Here $A$ is the area of the element, $c_{L}$ the dilatational-wave speed, $c_{S}$ the shear-wave speed, and $\varepsilon_{i j}$ the strain.

For the hydrodynamic elements, where the shear-wave velocity vanishes and the state of stress is hydrostatic, Eq. (55) reduces to 


$$
\mathrm{p}^{\mathrm{vis}}=\mu \rho \sqrt{\mathrm{A}} \mathrm{c} \dot{\mathrm{V}} / \mathrm{V}
$$

This pressure is added to the pressure obtained from the equation of state at each time step before computing nodal forces. However, only the pressures resulting from the equation of state are stored permanently.

When shocks are expected, an additional quadratic artificial viscosity of the Von Neumann type is added.

The general artificial viscosity of Eq. (55) can also be reduced to a onedimensional form appropriate for the beam elements. However, it was found that this has undesirable effects on the flexural response, so, instead, an artificial viscosity is only applied to the axial forces. This membrane viscosity is given by

$$
\mathrm{f}_{\mathrm{x} 2}^{\mathrm{vis}}=2 \mu \mathrm{A \rho c} \dot{\varepsilon}_{\mathrm{x}}
$$

where $\mathrm{A}$ is the cross-sectional area of the beam.

A second type of viscosity which was needed in this program is the antihourglass viscosity. The hourglass mode is shown in Fig. 4. It can be

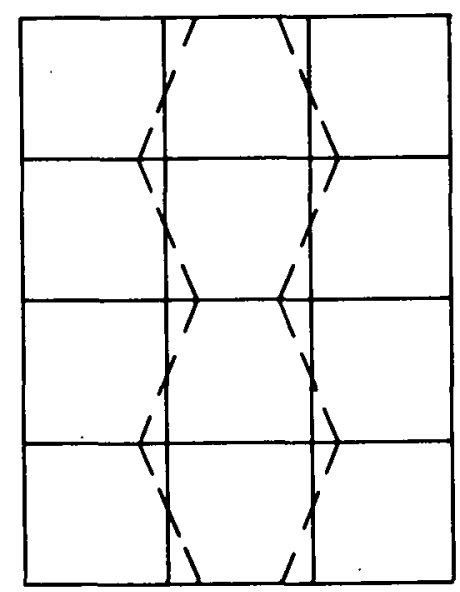

Fig. 4. Hourglass Type of Mesh Instability. (ANL Neg. No. 900-4796-1.)

seen that this mode of deformation of the quadrilateral element causes no volume change, and hence no pressure. Thus, any excitation which induces this mode of deformation is unresisted, and elements can become quite distorted in these modes. 
We have incorporated in STRAW a finite-element form of the Maenchen and Sack $^{30}$ rotational antihourglass viscosity. This viscosity is applied to the hourglass modes characterized by

$$
\begin{aligned}
& \dot{\mathrm{q}}_{1}=\omega_{14}-\omega_{23} ; \\
& \dot{\mathrm{q}}_{2}=\omega_{12}-\omega_{43},
\end{aligned}
$$

where $\omega_{I J}$ is the rate of rotation of side IJ.

The rotation of each side if defined by

$$
\omega_{I J}=\frac{1}{2}\left(\frac{\partial \dot{u}_{y}}{\partial x}-\frac{\partial \dot{u}_{x}}{\partial y}\right),
$$

where the right-hand side is evaluated along the side IJ. This yields

$$
\dot{\mathrm{q}}_{\mathrm{k}}=\mathrm{B}_{\mathrm{kiI}}^{\mathrm{H}} \dot{\mathrm{u}}_{\mathrm{iI}},
$$

where

$$
\mathrm{B}_{\mathrm{kiI}}^{\mathrm{H}}=\frac{1}{2}\left[\begin{array}{llllllll}
\overline{\mathrm{y}}_{41} & -\overline{\mathrm{x}}_{41} & -\overline{\mathrm{y}}_{32} & \overline{\mathrm{x}}_{32} & \overline{\mathrm{y}}_{32} & -\overline{\mathrm{x}}_{32} & -\overline{\mathrm{y}}_{41} & \overline{\mathrm{x}}_{41} \\
\overline{\mathrm{y}}_{21} & -\overline{\mathrm{x}}_{21} & -\overline{\mathrm{y}}_{21} & \overline{\mathrm{x}}_{21} & -\overline{\mathrm{y}}_{43} & \overline{\mathrm{x}}_{43} & \overline{\mathrm{y}}_{43} & -\overline{\mathrm{x}}_{43}
\end{array}\right]
$$

and

$$
\bar{x}_{I J}=x_{I J} /\left(x_{I J}^{2}+y_{I J}^{2}\right) ; \quad y_{I J}=\bar{y}_{I J} /\left(x_{I J}^{2}+y_{I J}^{2}\right)
$$

The generalized stresses corresponding to $\dot{q}_{K}$ are designated $Q_{k}$, and we choose a linear relationship of the form

$$
\mathrm{Q}_{\mathrm{k}}=\mu_{\mathrm{H}} \rho \mathrm{c} \sqrt{\Lambda} \dot{\mathrm{q}}_{\mathrm{k}}
$$

where $\mu$ is the antihourglass coefficient. The form of this relation between the generalized hourglass stresses and strain rates is similar in the form to the artificial viscosity in the volumetric deformation modes, so the range of values in $\mu_{H}$ is similar, although experience shows that $\mu_{H}$ should usually be lower than $\mu$ by a factor of 2 to 5 .

The nodal forces associated with $Q_{k}$ are obtained by use of Eq. (3). We note that the rate of energy dissipation in the element is 


$$
\dot{E}=\int_{V} Q_{k} \dot{q}_{k} d V
$$

By using Eqs. (56) and (60), we obtain

$$
\mathrm{f}_{i I}^{\mathrm{H}}=\mathrm{B}_{k i I}^{\mathrm{H}} \mathrm{Q}_{k} \mathrm{~V} \text {. }
$$

Thus, the antihourglass viscosity simply introduces another set of internal nodal forces which are added to those resulting from the pressure in the element.

\section{F. Sliding Interface}

At the fluid-solid interface, relative sliding of the fluid and solid is permitted. The treatment of sliding is simplified in quasi-Eulerian formulations, because the fluid nodes can be constrained to remain contiguous to the structural nodes. On the other hand, when Lagrangian meshes are used for the fluid, the fluid nodes will move relative to the structure, so rather cumbersome algorithms that treat nodes on a sliding interface that are not aligned must be included.

The node structure at a sliding interface as used herein is shown in Fig. 5. At each point of the interface, we have two nodes: one fluid node and one structural node. For each pair, a local coordinate system $(t, n)$ is set up so that

$t$ is the tangent to the sliding interface;

$\mathrm{n}$ is $90^{\circ}$ counterclockwise from $t$.

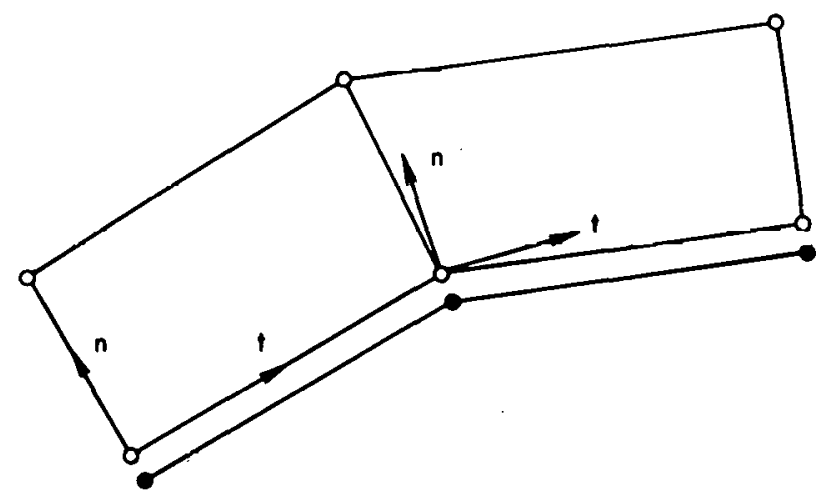

- structural nodes

- fluid nodes

Fig. 5. Sliding Interfaces. (ANL Neg. No. 900-78-17, Rev. 1.) 
Whenever a corner occurs in the interface, $t$. is the average of the two tangent directions.

The grid and material velocities of the fluid are specified by the following:

$$
\begin{aligned}
& \dot{\mathrm{u}}_{\mathrm{Fn}}^{\mathrm{G}}=\dot{\mathrm{u}}_{\mathrm{Sn}} ; \\
& \dot{\mathrm{u}}_{\mathrm{Ft}}=\dot{\mathrm{u}}_{\mathrm{St}} ; \\
& \dot{\mathrm{u}}_{\mathrm{Fn}}=\dot{\mathrm{u}}_{\mathrm{Sn}},
\end{aligned}
$$

where the subscripts $S$ and $F$ refer to the structure and fluld, respectively.

The conditions of Eqs. (65a) and (65b) are imposed directly. The condition Eq. (65c) is enforced through the nodal forces. After all internal nodal forces have been summed and prior to the calculation of the nodal accelerations by Eq. (1), the nodal forces at each pair of nodes on the sliding interface are transformed into the $(t, n)$ system. The normal components of the fluid and structural node are then redefined by

$$
\begin{aligned}
& f_{S n} \leftarrow f_{S n}+f_{F n} ; \\
& f_{F n} \leftarrow f_{S n}
\end{aligned}
$$

Thus the normal components of nodal forces are set equal, which results in equality of the normal components of the accelerations. Therefore, a palr of nodes at the interface in effect only share 3 translational degrees of freedom: $\dot{u}_{S n}, \dot{u}_{S t}$, and $\dot{u}_{F t}$. 


\section{DESCRIPTION OF MODELS}

We will here describe the modeling procedures and philosophies employed in our treatment of the subassembly problem by the two-dimensional program STRAW. As mentioned previously, the two major difficulties in modeling the subassemblies are: (1) the three-dimensional character of the problem, and (2) the complex intermingling of structural components and fluid, with narrow fluid channels that must be treated by a limited number of degrees of freedom. Because of the inordinate computational expense associated with complete threedimensional analyses, they had to be ruled out for the major part of the studies, and alternative models which capture limited portions of the three dimensionality had to be developed. We denote these models which were constructed by augmenting standard two-dimensional models by $2 \mathrm{D}+$.

A cross section of a subassembly cluster is shown in Fig. 6. The dimensions of an individual subassembly are shown in Fig. 7, the view being per-

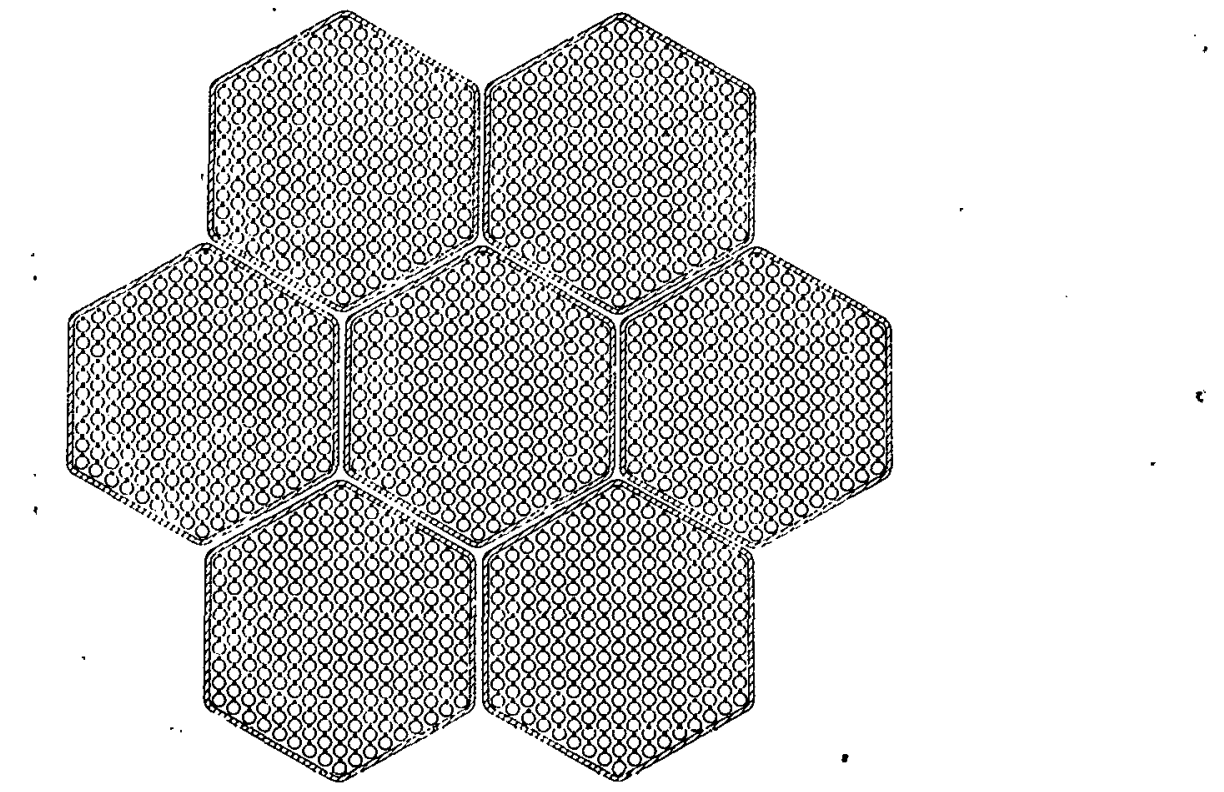

Fig. 6. Cross Section of Subassembly Cluster. (ANL Neg. No. 900-75-304.)

pendicular to the axis of the fuel pins and hexcan. As can be seen, the only symmetry in these problems is a rotational periodicity of $30^{\circ}$. The twodimensional models are formed in this plane, as shown by the finite-element model of Fig. 8. It includes an accident hexcan and two layers of adjacent subassemblies. This model takes advantage of the $30^{\circ}$ periodicity by using a 


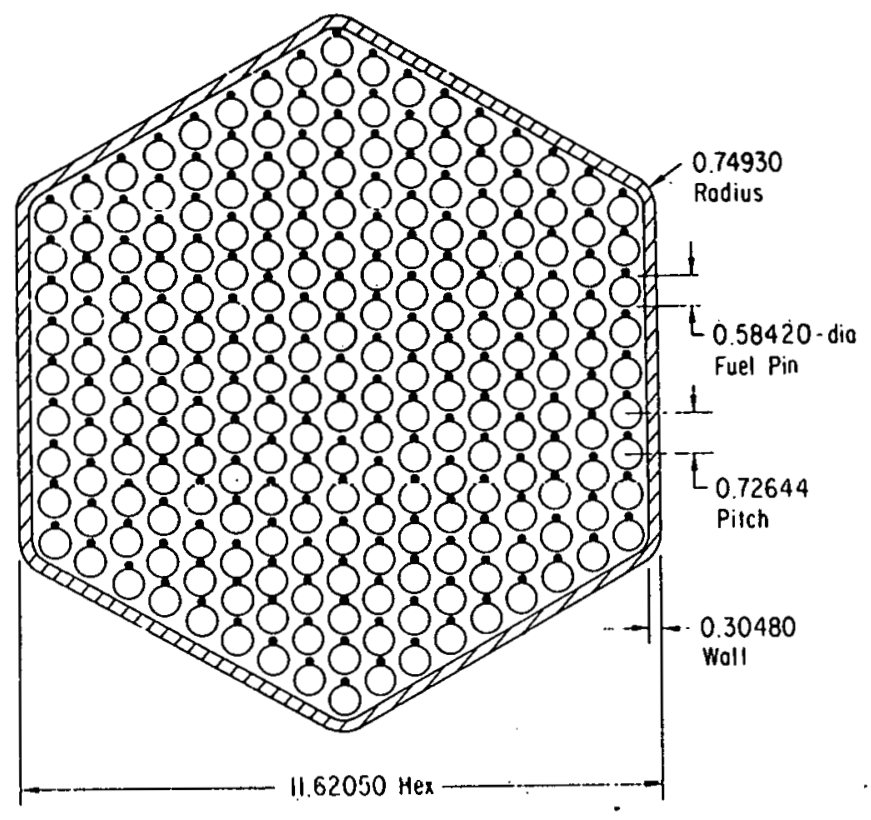

Fig. 7. Subassembly Configuration (all dimensions in $\mathrm{cm}$ ). (ANL Neg. No. 900-77-1146.)

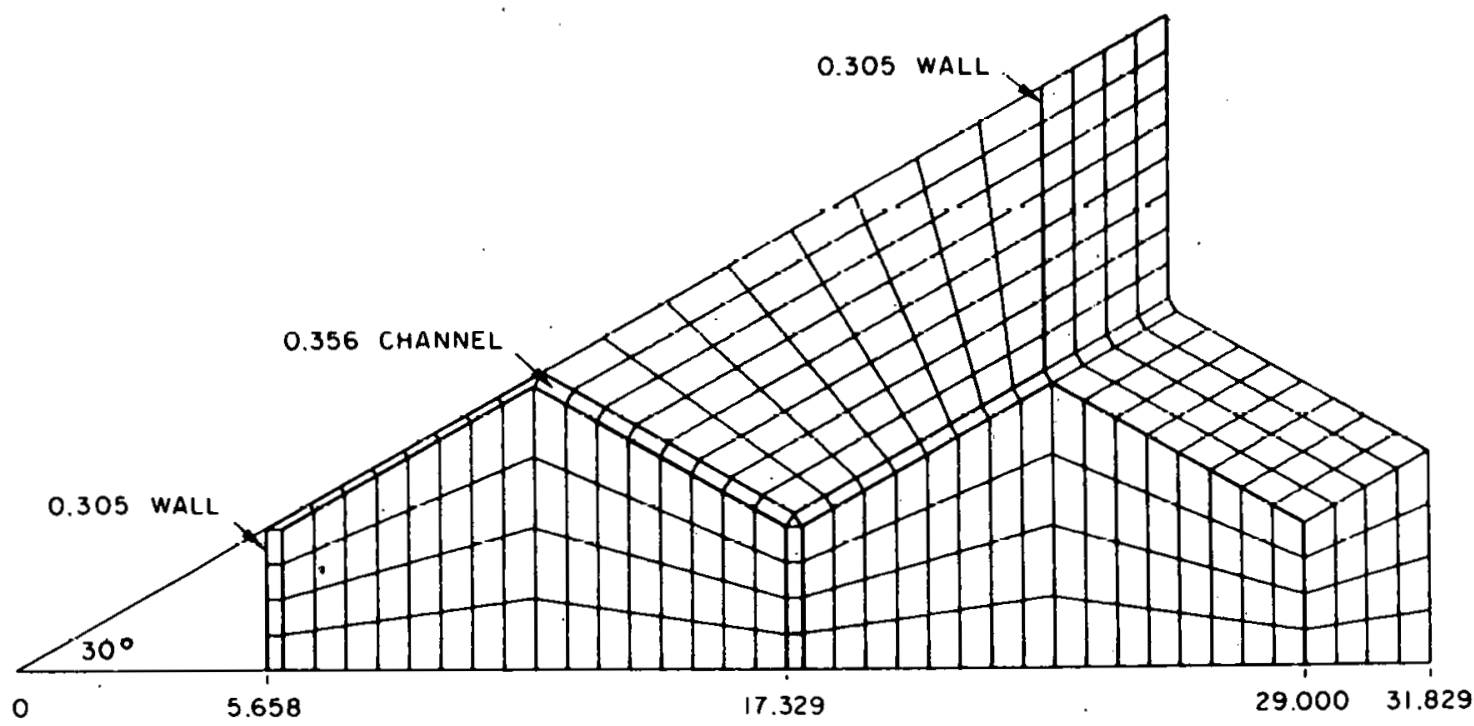

Fig. 8. Two-dimensional Model of Subassembly Cluster (all dimensions in $\mathrm{cm}$ ).

(ANL Neg. No. 900-5440, Rev. 1.) 
one-twelfth section and thus is limited to symmetric loads in the center of the accident hexcan.

The three-dimensional aspects of the STRAW 2D+ model are illustrated in Fig. 9. As can be seen from the figure, the area of energy release is expected

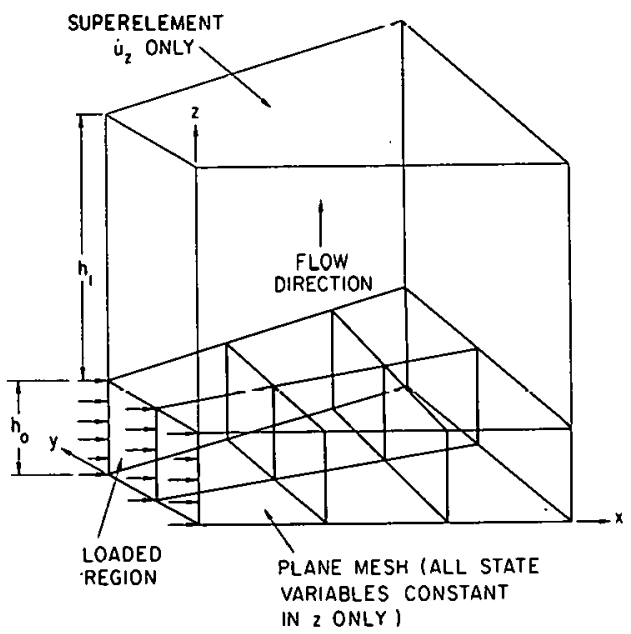

Fig. 9. Three-dimensional Aspect of the STRAW 2D+ Model. (ANL Neg. No. 900-4768.)

to be uniform in the $z$ direction, which coincides with the axis of the subassembly. The behavior in this energy-release zone is represented by a plane mesh of two-dimensional elements. The axial flow is modeled by a set of onedimensional elements which are superimposed on the two-dimensional plane mesh, with the axis of the one-dimensional flow perpendicular to the plane mesh. The flow is assumed to by symmetric about the midplane of the energy-release zone, so that in addition to the upward flow model illustrated in Fig. 9, a downward flow of equal velocity is assumed in a lower column. As many plane elements as desired can be superimposed by a single element of the axial flow model; the axial flow is then driven by a area-weighted average of the pressure in the plane elements which are superimposed by the axial flow elements. The axial flow elements are therefore called "superelements." Only vertical flow (in the $z$ direction) is modeled in the superelements; any flow in the $x$ and $y$ directions above and below the energy-release zone is neglected.

Although the initial pressure waves propagate through both the solid fuel pins and the sodium, only the motion of the coolant is considered in superelements, for it is assumed that the fuel pins are not completely ruptured, 
but maintain axial coherence, so that very large motions w111 not be experlenced by the fuel pins. Calculations have shown that the coolant exhibits rather large displacements. For example, when the energy source generates a pressure of about $7 \mathrm{MPa}$ for about $4 \mathrm{~ms}$, the coolant moves a distance of the order of $1 \mathrm{~cm}$. Thus it is evident that most of the energy imparted to the axial column is employed in overcoming the inertial and viscous resistance of the fluid; probably very little energy is expended in the acoustic wave that moves through the fuel pins. Therefore, in the axial model, attention is restricted to the fluid; the pins are treated as an inert, incompressible constituent.

The hexcan walls are treated as strictly two-dimensional in the $x-y$ plane, with the entire strength derived from flexural and membrane action in this plane. Hence, the walls of the hexcan are essentially beams in a state of plane strain. The membrane action and flexure in $z$ direction are neglected in the accident hexcan, for energy sources are assumed to extend vertically from 20 to $30 \mathrm{~cm}$, whereas the distance across flats is only $6.9 \mathrm{~cm}$, so that the effects of flexure and membrane action in $z$ direction should be considerably less than that in the $x-y$ plane. Furthermore, since the energy source is considered to be centered within the energy-release hexcan, no overall bending action of this hexcan is expected. On the other hand, the hexcan adjacent to the accident hexcan should exhibit substantial overall flexure; therefore, beam elements in the $x-y$ plane are not sufficient to capture the salient characteristics of its response, and thus beam elements are placed in the zdirection to capture the flexure resistance of the adjacent hexcan. Whereas the $x-y-p l a n e$ constitutive characterization of the beam elements can be based directly on uniaxial strain tests and standard plasticity theory, these transverse beams include parameters that depend on the response and can only be determined from three-dimensional experiments or analysis.

The channels were modeled by quasi-Eulerian elements. Sliding interfaces are included between the beam elements and quasi-Eulerian fluid elements in the channels.

In contrast to Ref. 4, a continuum approach has been chosen for characterizing the internals. The following are the reasons for this choice: since there are 217 fuel pins per subassembly, a discrete model of the internals with a one-to-one correspondence between fuel pins and nodes would 
require of the order of 600 nodes (one for each fuel pin, about 3 for each of the flow channels). Experience with COBRA has shown that models of such refinement entail tremendous computational costs for the fluid flow alone, and while coarser models have proved effective in treating the fluid flow, it is doubtful that a model based on actual pin interaction would prove accurate unless the pins are treated in their actual size; (2) while it is possible to determine from experiments and analysis the overall behavior of fuel-pin matrices, the determination of individual pin interactions is more difficult both experimentally and analytically.

Once a continuum approach is chosen, it is necessary to separate the behavior of the fluid from that of the fuel-bundle lattice. For this purpose, the internals are represented by two layers of elements as shown in Fig. 10.

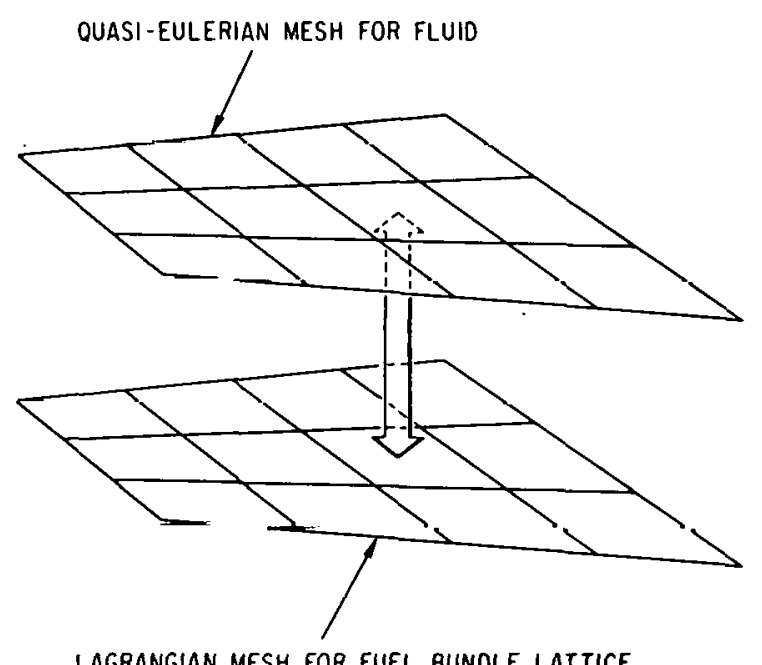

Fig. 10. Mesh Representation of Subassembly Internals. (ANL Neg. No. 900-77-446.)

The fuel-bundle lattice is treated by a Lagrangian mesh. The constitutive properties of the lattice are based entirely on their response in the absence of the fluid. The constitutive behavior of the fluid depends on the motion of the fluid relative to the fuel bundles as well as on the dilation of the mesh and fuel bundles. Therefore, it is convenient to associate a fluid element with a single-pin matrix element, so the quasi-Eulerian description has been chosen for the fluid mesh.

In earlier studies, ${ }^{31}$ the fuel pin (that is, both the cladding and the fuel) was characterized as incompressible compared to the coolant, and the 
shear strength of the fuel-pin matrix was ignored. At that time, an experimental program to determine the constitutive characteristics of the fuel bundles was contemplated. However, this experimental program is still not started, so constitutive equations for the fuel bundles were developed analyticaliy by energy considerations. In addition, by noting the strains in the fuel bundle associated with certain homogenized states of stress, it is possible to relate the energy deposition in the internals to the likelihood of failure of the fuel bundles. The material properties of the fuel-pin matrix are represented by a Coulomb-Mohr elastic-plastic model, so that the frictional effects of relative pin sliding are included. The analytical model of the fuel-bundle matrix considers two mechanisms: (1) the decrease in distance between fuel pins which results from the twisting of the wire wraps and flexure of the pins, and (2) the decrease in the effective dimension of the fuel pin arising from deformation at the point of wrapper-pin contact. 


\section{RESULTS}

The first set of results are included to indicate the performance of the quasi-Eulerian elements in a one-dimensional wave-propagation problem. The mesh is shown in Fig. 11. Although two-dimensional elements are used, the problem is one-dimensional because no motion is permitted in the y-direction. The right-hand boundary nodes of the mesh, nodes $\underline{41}$ and $\underline{82}$, are fixed.
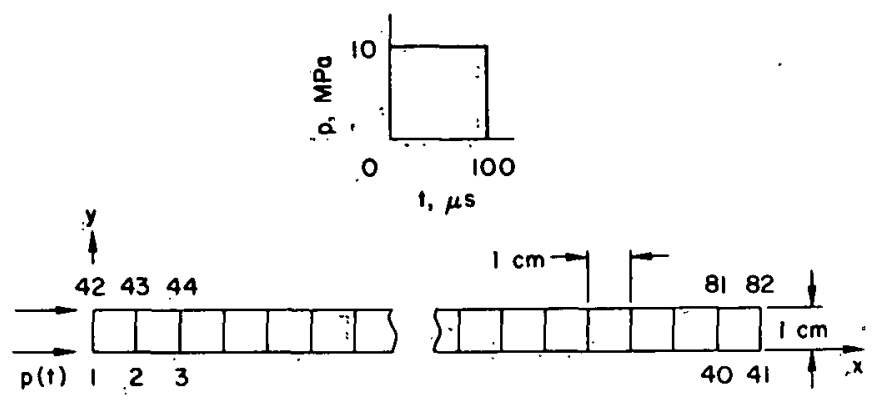

Fig. 11. One-dimensional Wave-propagation Problem. (ANL Neg. No. 900-78-11.)

Three types of description were considered:

1. a Lagrangian description, in which mesh nodes move with the matcrial;

2. an Eulerian description, in which all nodes are fixed in space, except the first pair of nodes, nodes $\underline{1}$ and $\underline{42}$, which move with the material;

3. a quasi-Eulerian mesh, in which the first two nodes, $\underline{1}$ and $\underline{42}$, are Lagrangian, and the grid velocities of the remaining nodes are obtained by linearly interpolating between the left- and right-handside nodes:

$\dot{u}_{x I}^{G}=\dot{u}_{x I}^{M}\left(1-\frac{x_{I}}{40}\right)$

Other data for this solution are $c$ (wavespeed) $=1 \times 10^{5} \mathrm{~cm} / \mathrm{s} ; \Delta t=2 \mu \mathrm{s} ; \frac{\ell}{c}=10 \mu \mathrm{s}$.

The problems were run significantly below the stability limit because the goal was to obtain a converged solution for the mesh. 
The results for the pressure at $x=0.5 \mathrm{~cm}$ and $\mathrm{x}=10.5 \mathrm{~cm}$ are shown for the three cases in Figs. 12 and 13. As can be seen, the predictions with the three types of mesh description are almost identical and compare well with the analytic solution. However, the problem is not a severe test, for the maximum velocities are only $1000 \mathrm{~cm} / \mathrm{s}$, so that the momentum-transport terms play a small role.

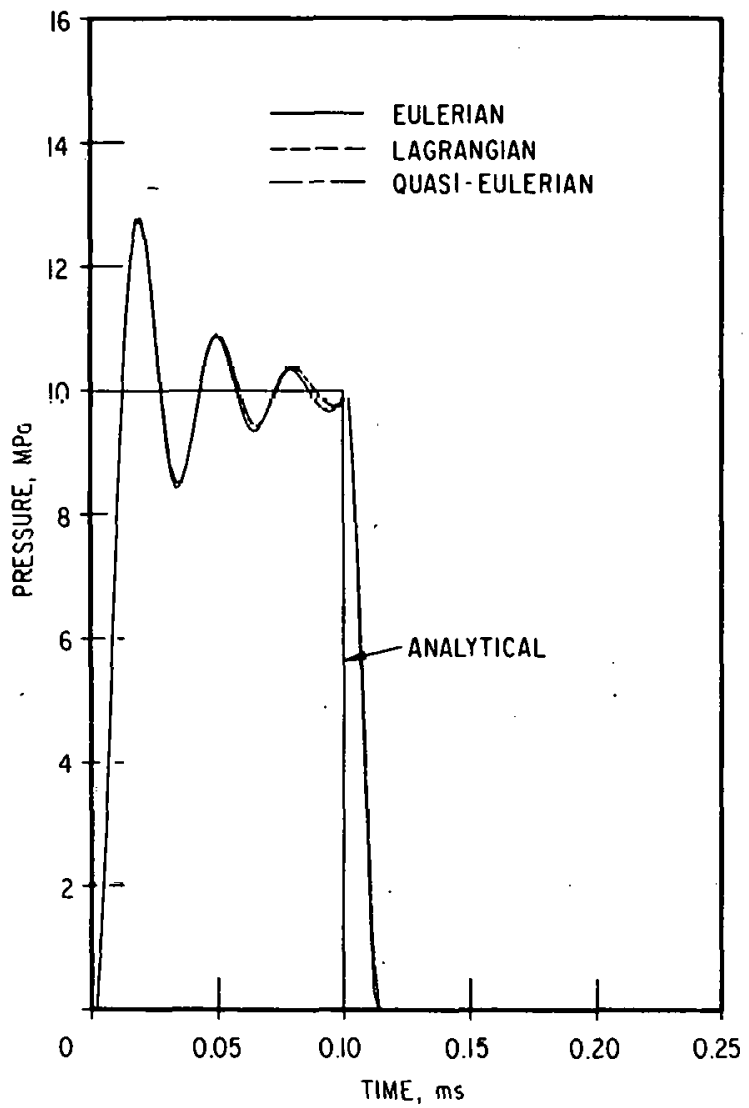

Fig. 12. Pressure at $x=0.5 \mathrm{~cm}$ for Lagrangian, Eulerian, and Quasi-EuZerian Descriptions.

(ANL Neg. No. 900-78-10.)

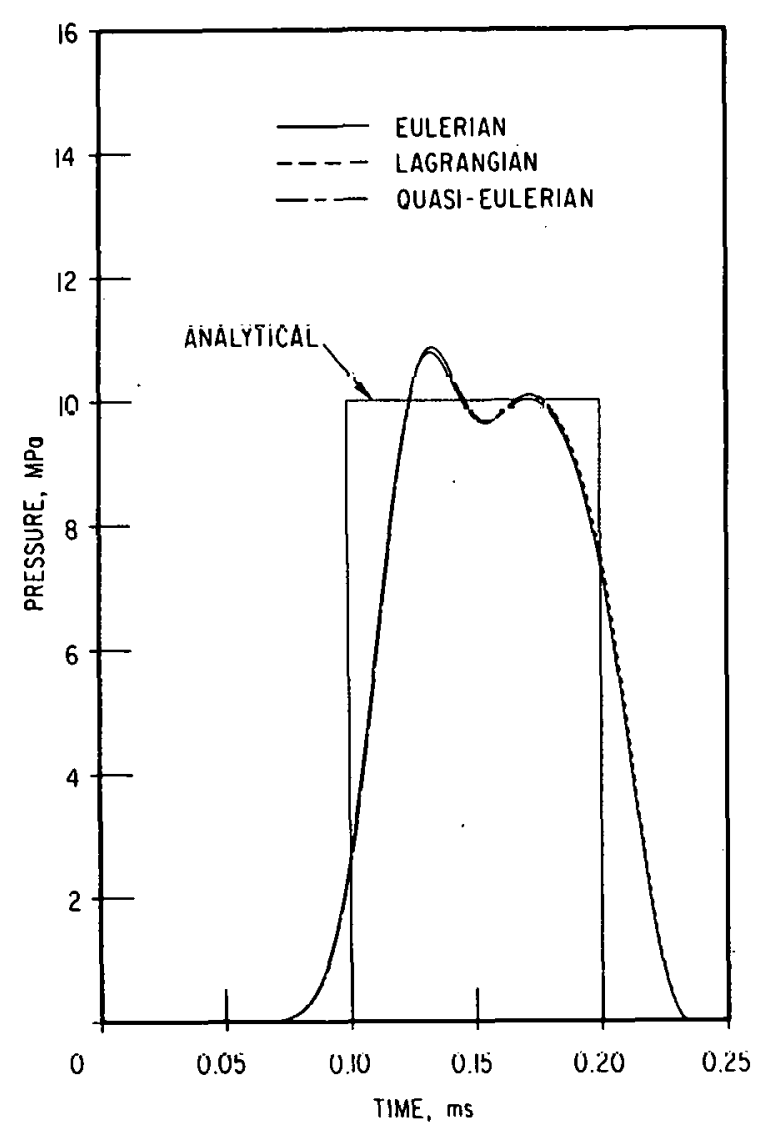

Fi.g. 13. Pressure at $x=10.5 \mathrm{~cm}$ for Lagrangian, EuZerian, and Quasi-Eulerian Descriptions.

(ANL Neg. No. 900-78-13.)

It is of interest to note that the extrapolation of velocities described previously has a significant effect on the results. This is evident in Figs. 14 and 15, which show the results with and without the extrapolation. The extrapolation can be seen to provide an artificial viscosity which reduces the amplitude of the oscillations.

In order to illustrate the performance of the quasi-Eulerian elements in channels, we have considered two different models for which experimental 


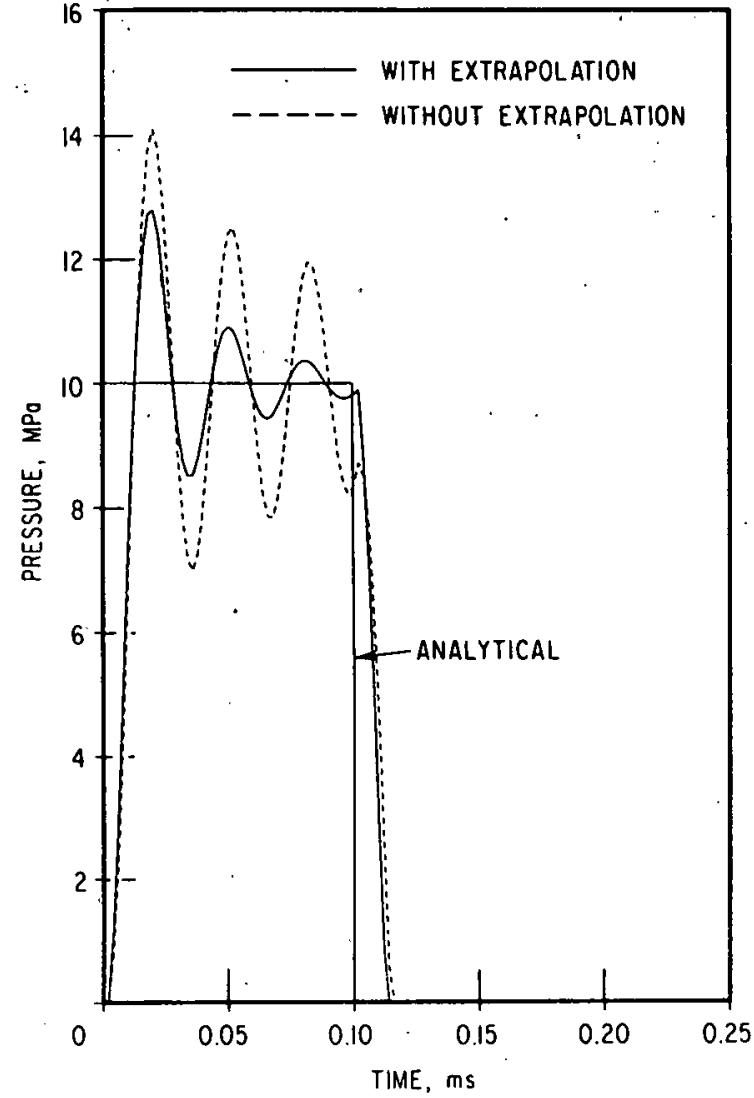

Fig. 14. Pressure at $x=0.5 \mathrm{~cm}$ for Quasi-EuZerian Description with and without Velocity Extrapolation.

(ANL Neg. No. 900-78-12.)

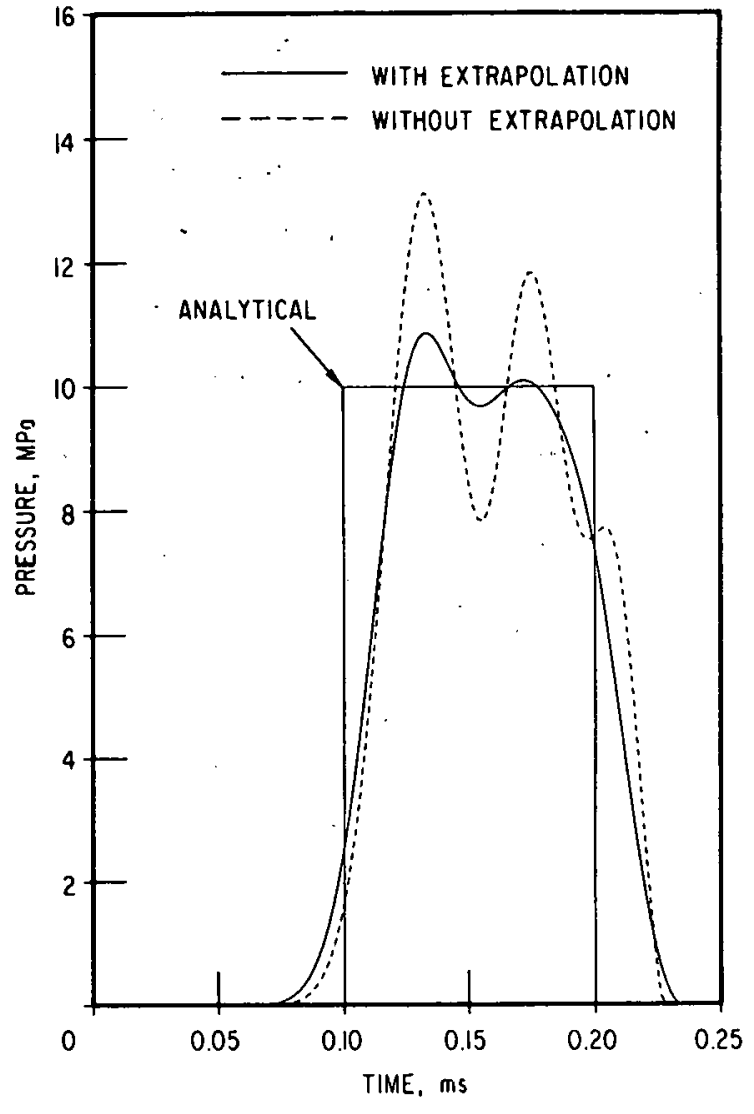

Fig. 15. Pressure at $x=10.5 \mathrm{~cm}$ for Quasi-EuZerian Description with and without Velocity Extrapolation.

(ANL Neg. No. 900-78-19.)

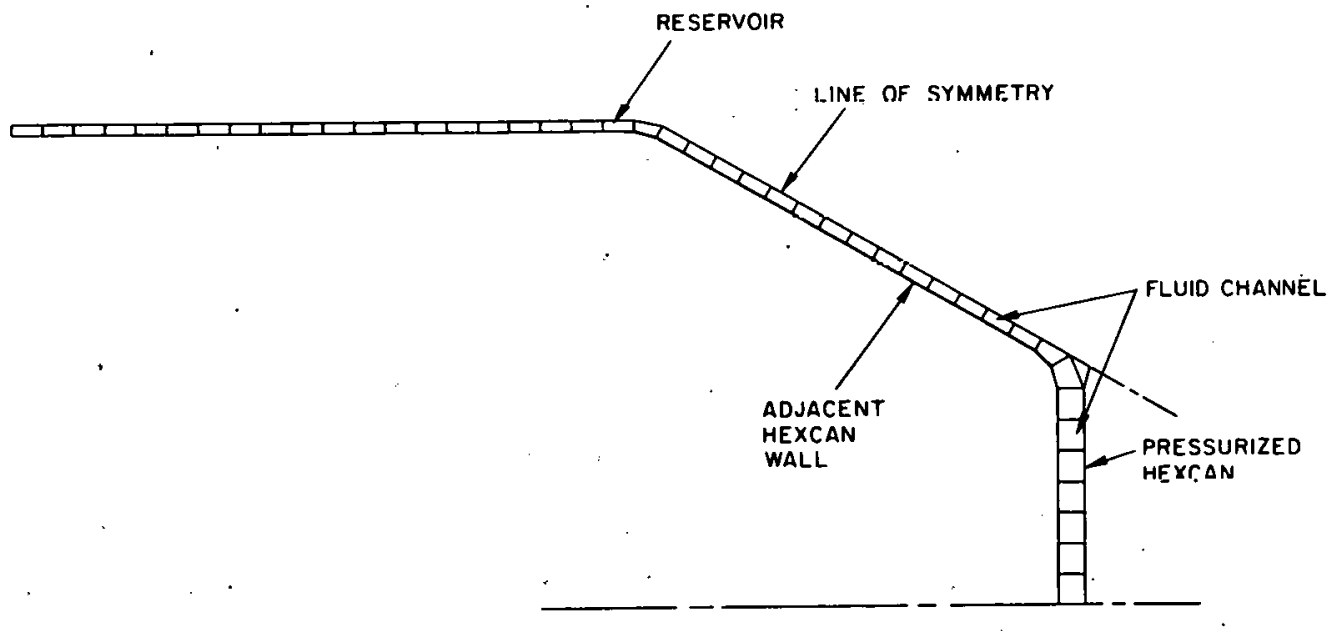

Fig. 16. Simplified Model of an SRI Experiment. (ANL Neg. No. 900-78-6.) 
results are available. The first model is a simplified mode1, shown in Fig. 16, which represents only the accident (pressurized) subassembly, the channel of fluid, and the adjacent subassembly. In addition, a reservoir is included to receive the flow from the channels as the subassembly wa11s are squeezed together. The fluid elements in the channel are quasi-Eulerian, while those in the reservoir are Lagrangian.

This model represents an SRI experiment ${ }^{8}$ which is depicted in Fig. 17. In this experiment, a slow charge was detonated in the center subassembly,

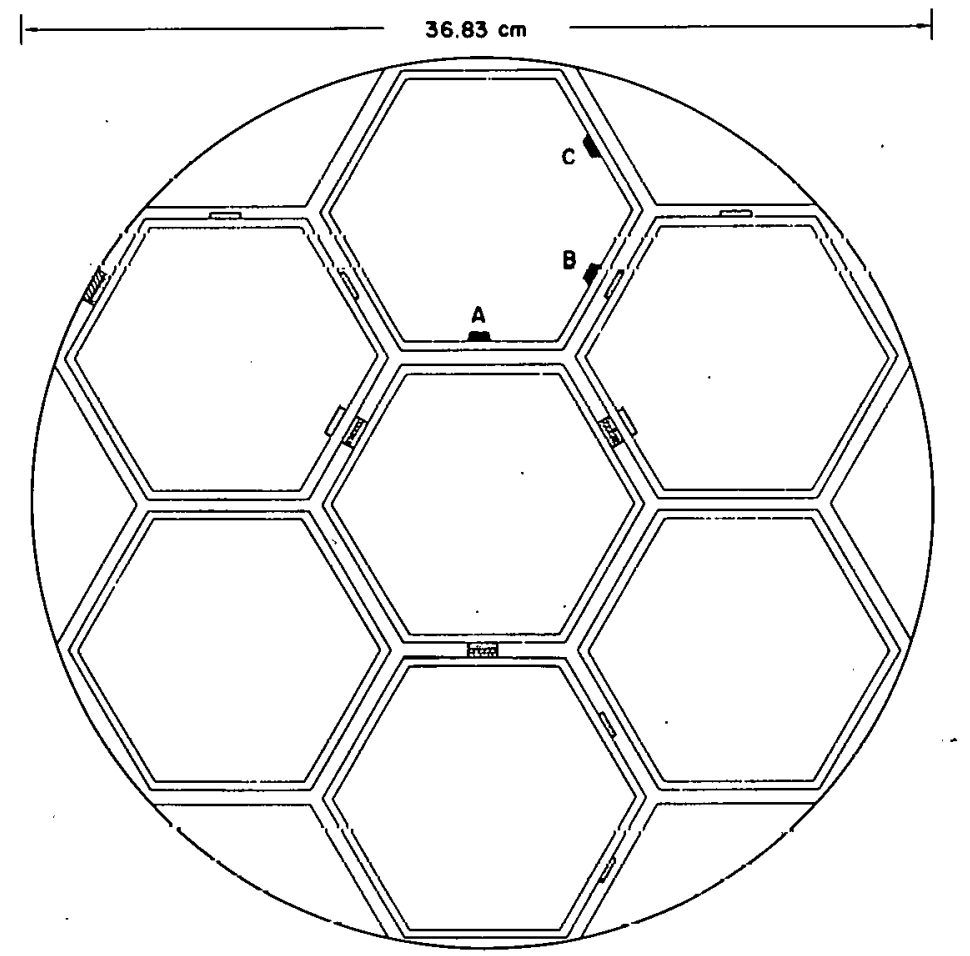

Eig. 17. SRI Experimental Model Cross Section. of Subassembly Cluster. (ANL Neg. No. 900-78-7.)

which resulted in the pressure loading shown in Fig. 18. In the model this pressure was applied uniformly on the inside walls of the center hexcan.

The wall material is annealed Type 316 stainless steel. It. is modeled by an elastic-plastic law in a state of uniaxial plane strain. Isotropic hardening is included, but no strain-rate effects are considered. The initial hardening curve was obtained as part of the experimental program and is given in Table 4. Other material data for the steel are 


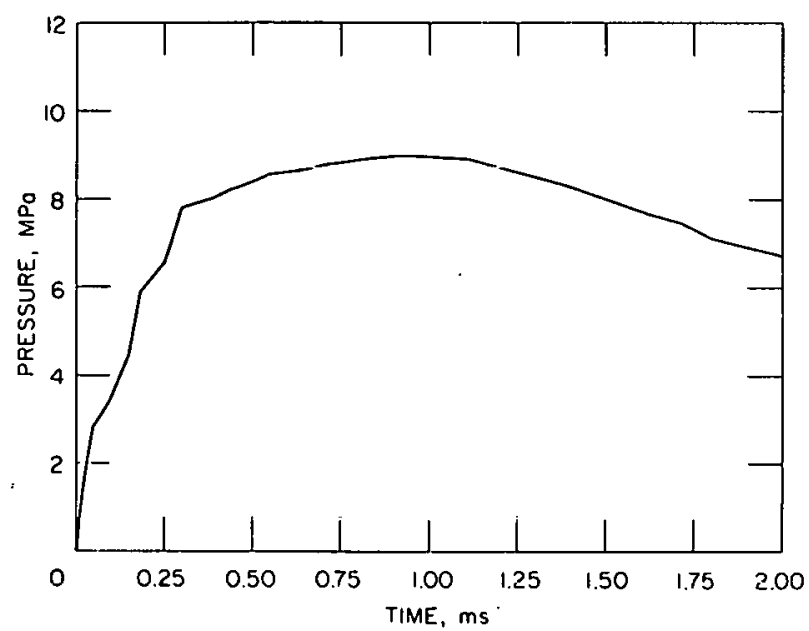

Fig. 18. Pressure on Accident Subassembly. (ANL Neg. No. 900-78-18.)

Table IV. Strain-Stress Values of Materials

\section{Annealed 316 Stainless Steel}

Strain $(\mathrm{m} / \mathrm{m})$

0.000915

$0.00 \overline{2}$

0.039

0.070

0.170

0.730

2.320

Stress (MPa)

194.2

225.1

362.1

446.2

627.5

1237.8

1490.5

6061-T6 Aluminum

Strain (m/m)

Stress (MPa)

0.00348

283.2

0.00465

326.9

0.009

407.4

0.100 


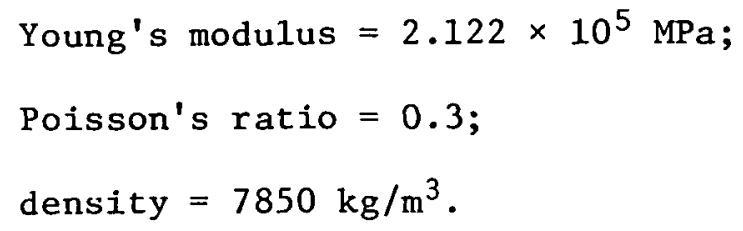

The fluid between the hexcans in the experiment is a lightweight transformer ofl. It is modeled as a compressible, inviscid fluid with a linear relationship between pressure and volume change. A pressure cutoff was included so that no tensile pressures are permitted. The numerical values used for the material data are

$$
\begin{aligned}
& \text { Bulk modulus }=1.67 \times 10^{3} \mathrm{MPa} ; \\
& \text { density }=850 \mathrm{~kg} / \mathrm{m}^{3} .
\end{aligned}
$$

The time steps given by the axial frequency and bending frequency of the beam, Eqs. (49-51), and for the fluid element are

$$
\begin{aligned}
& \Delta t_{\text {Axial }}=0.8 \mu \mathrm{s} ; \\
& \Delta t_{\text {Bend }}=0.6 \mu \mathrm{s} ; \\
& \Delta t_{\text {Fluid }}=1.3 \mu \mathrm{s},
\end{aligned}
$$

so that the structural frequency is the limiting factor on the time step. A time step of 0.2 us was used; the time step was reduced below the linear stability to insure stability in the presence of geometric nonlinearities, hut. we have not examined how much of this reduction is necessary.

The analytical results for the pressure in the channel at points $A$ and $B$ in Fig. 17 are compared to the experimental results in Figs. 19 and 20, respectively. As can be seen, the average pressure for both the experiment and computation is about $22 \%$ of the pressure in the center hexcan. Furthermore, for point A, the computed pressures exhibit a drop at $0.6 \mathrm{~ms}$, which corresponds to a pressure drop at $0.5 \mathrm{~ms}$ in the experiment.

Large motion of the channel was observed from the numerical results, thus demonstrating the need for quasi-Eulerian elements. The amount of fluid expelled from the channel can be gauged by the motion of the Lagrangian elements in the reservoir.

A more complete finite-element model for these experiments is shown in Fig. 21. In this model, the complete adjacent hexcan is included. The same 


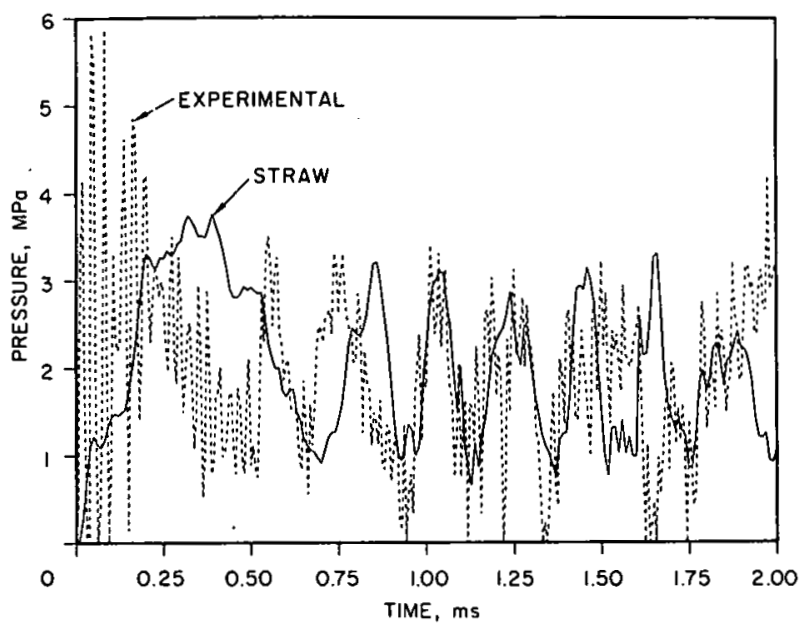

Fig. 19. Pressure History in the Channel at Point $A$ of Simplified Model. (ANL Neg. No. 900-78-11.)

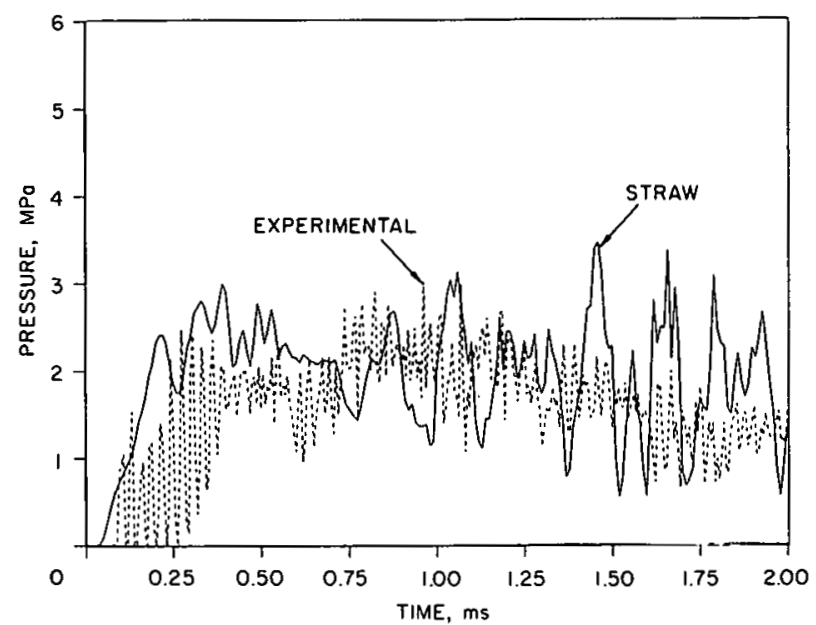

Fig. 20. Pressure History in the Channel at Point $B$ of Simplified Model.

(ANL Neg. No. 900-78-8.)

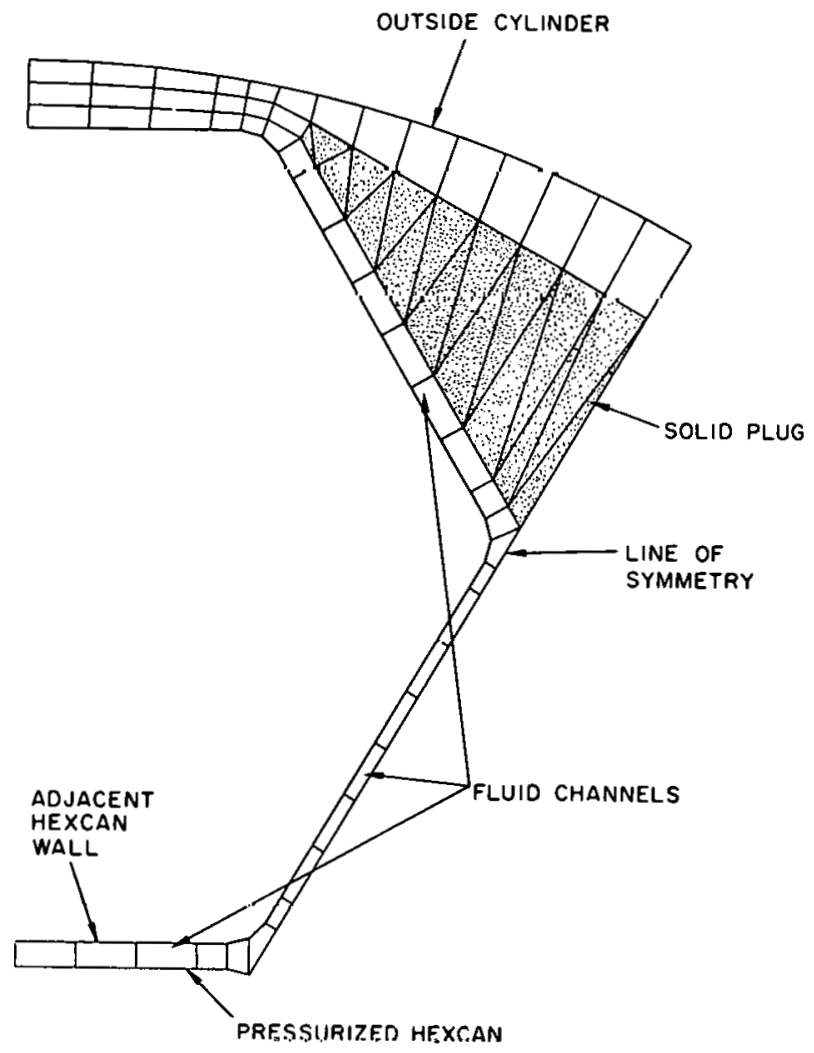

Eig. 21. Complete Modez of an SRI Experiment. (ANL Neg. No. 900-78-4.) 
material characterizations as in the previous model were used except for the outside cylinder, which was 6061-T6 aluminum. Its initial hardening curve is also given in Table 4. The other pertinent data for aluminum are

$$
\begin{aligned}
& \text { Young's modulus }=0.814 \times 10^{5} \mathrm{MPa} ; \\
& \text { Poisson's ratio }=0.3 ; \\
& \text { density }=2540 \mathrm{~kg} / \mathrm{m}^{3} .
\end{aligned}
$$

The plugs used in the experiment were aluminum prisms and modeled by using Lagrangian continuum elements. The same pressure loading as in the simplified model was used.

The pressules il polnts $A, B$, and $C$ in Fig. 1 il in the channel are r.nmpared to the experimental records in Figs. 22 to 24 . Again, the mean value of the

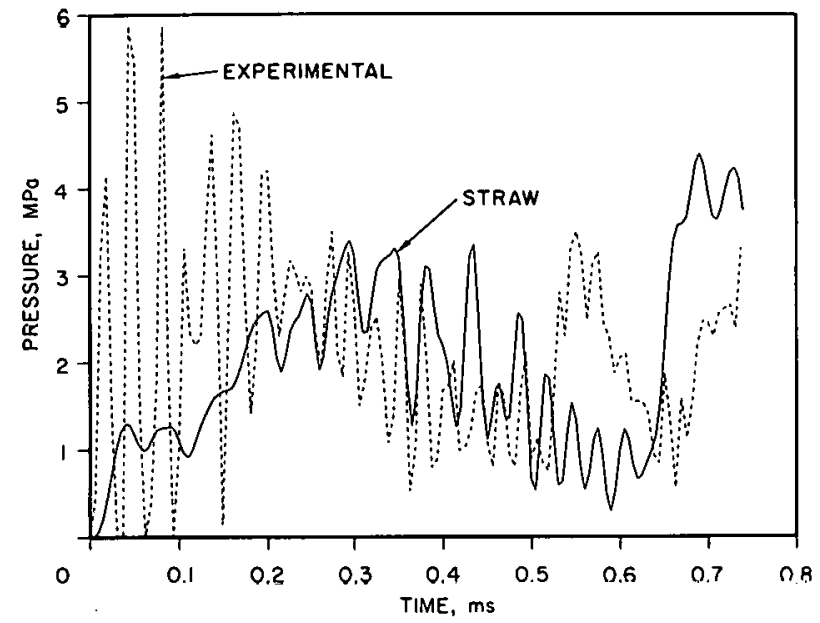

Fig. 22. Fressure History in the Channel at Point $A$ of Complete Modez. (ANL Neg. No. 900-78-3.)

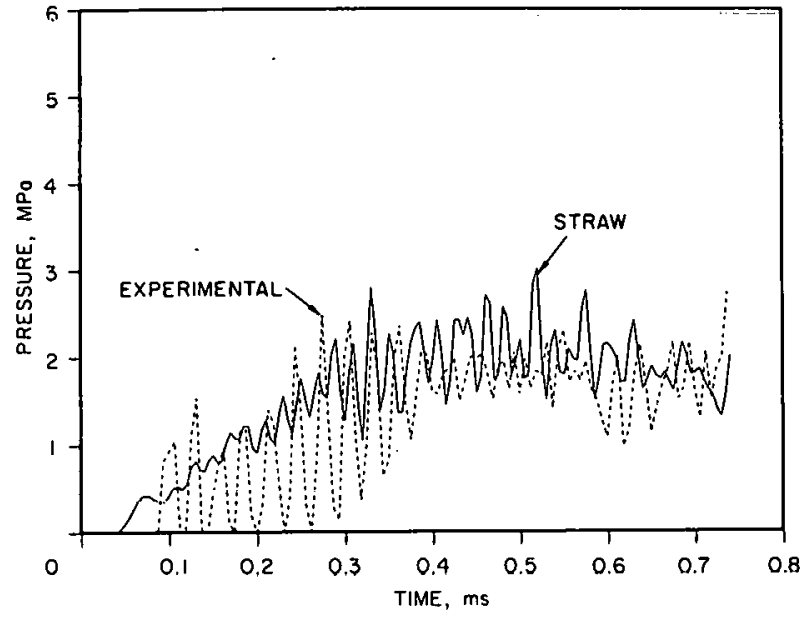

Fig. 23. Pressure History in the Channel at Point. $B$ of Complete Model. (ANL Neg. No. 900-78-2.)

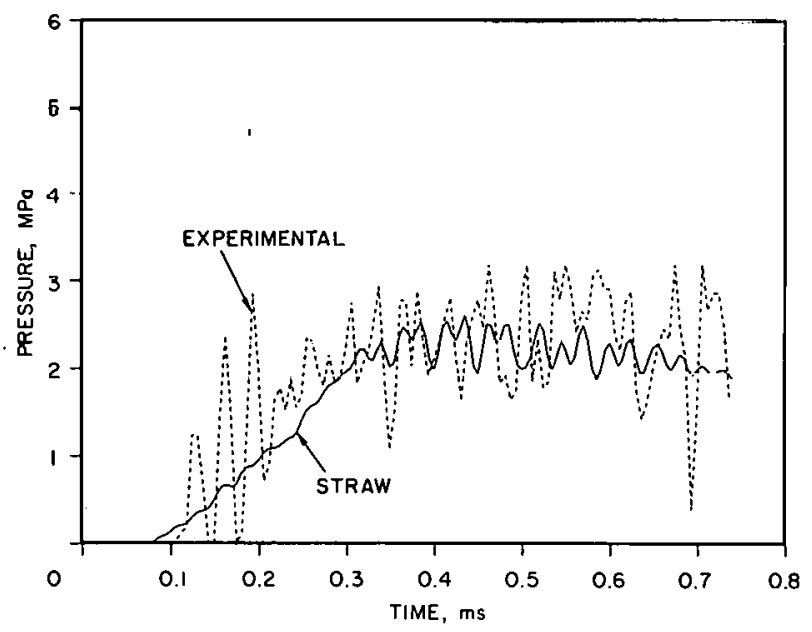

Fig. 24. Pressure History in the Channel at Point $C$ of Complete Model. (ANL Neg. No. 900-78-9.) 
pressure compares well with experimental values. The computations also exhibit the following features of the experimental records:

1. Except for the oscillations, the peak pressure at $\mathrm{A}$ is about $3.0 \mathrm{MPa}$ at $0.3 \mathrm{~ms}$ and decays to $1.0 \mathrm{MPa}$ at $0.5 \mathrm{~ms}$, although the experimental record exhibits an oscillation at $0.6 \mathrm{~ms}$ which is not seen until $0.7 \mathrm{~ms}$ in the computation.

2. The records at $B$ and $C$ reach a peak of about $2 \mathrm{MPa}$ at $0.3 \mathrm{~ms}$ and decay slowly from the time. Deformed confiturations of this model are shown in Fig. 25.

The complete model, shown in Fig. 8, represents the accident subassembly and the next two rows of adjacent subassemblies. In addition, four layers of fluid elements are added beyond the far walls of the second row of subassemblies. The outside nodes are free, so that because of the tension cutoff, any compressive waves which reach the outside boundaries of the model will spall the outside elements and cause little spurious reflection. The channels and the coolant within the subassemblies are modeled by quasi-Eulerian elements. Axial flow perpendicular to the plane of the model was also included.

This model was loaded with a very energetic source with pressure-time history as follows:

$\begin{array}{rr}\text { Time, ms } & \text { Pressure, MPa } \\ 0.0 & 0.00 \\ 0.2 & 68.75 \\ 0.4 & 0.00\end{array}$

Figure 26 shows the deformed configuration of the mesh. The rapid attenuation of deformation away from the pressurized subassembly is quite evident from the figures. It is even more apparent in the maximum strains predicted in the hexcan flats. In the accident hexcan, the maximum strain at the outside surface of the center of the flat is $14.8 \%$. In the adjacent subassembly, the maximum strains opposite this point are $5.0 \%$, while the strains in the midflat of the far walls are $1.5 \%$. In the second row of sub-. assemblies, the maximum strain is $3.8 \%$. Thus, the heterogeneous geometry and structure of the subassemblies leads to a considerably greater reduction in damage than in homogeneous, cylindrical geometries. 

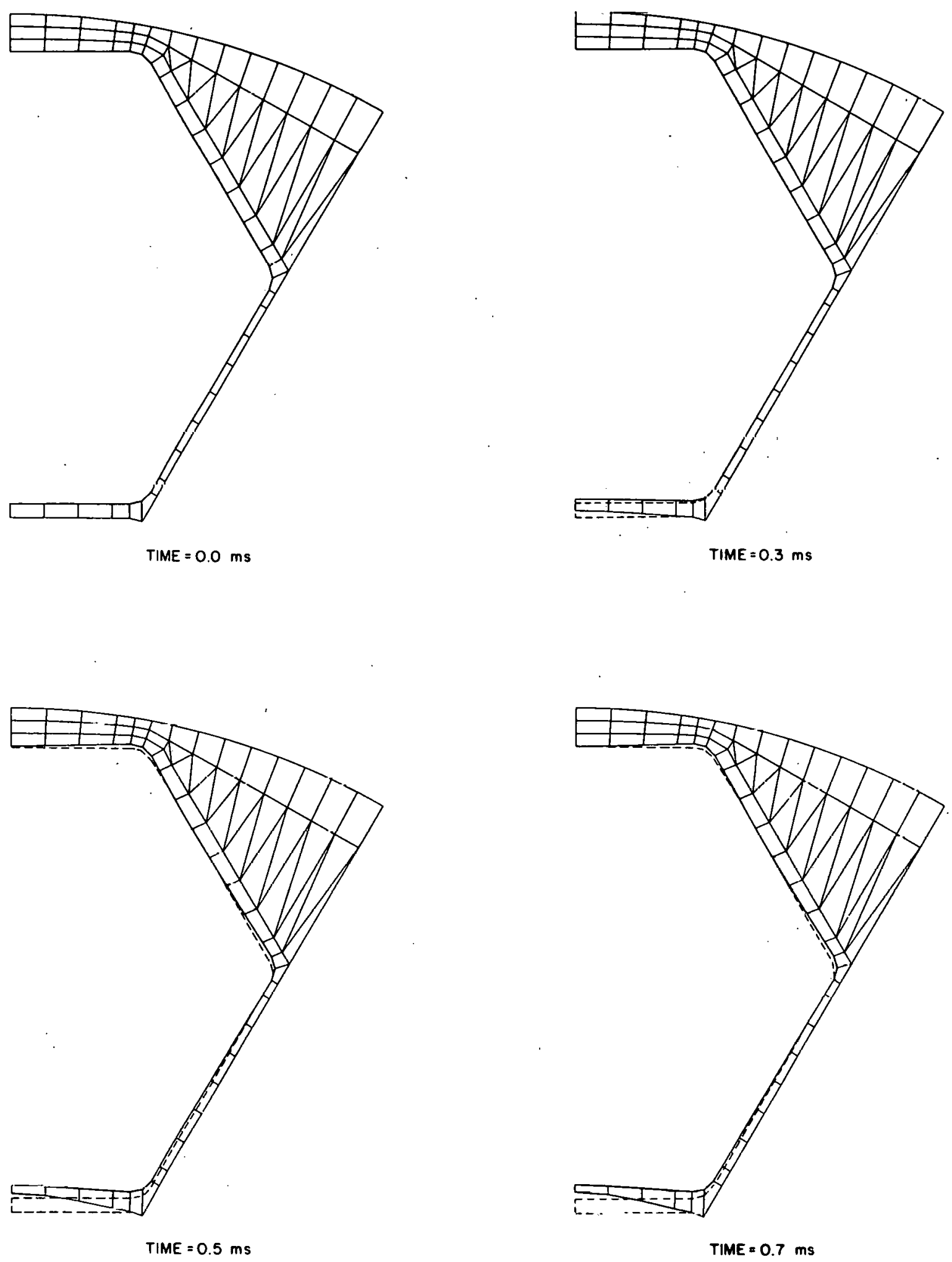

Fig. 25. Deformed Configurations of Complete Model. (ANL Neg. No. 900-78-117.) 


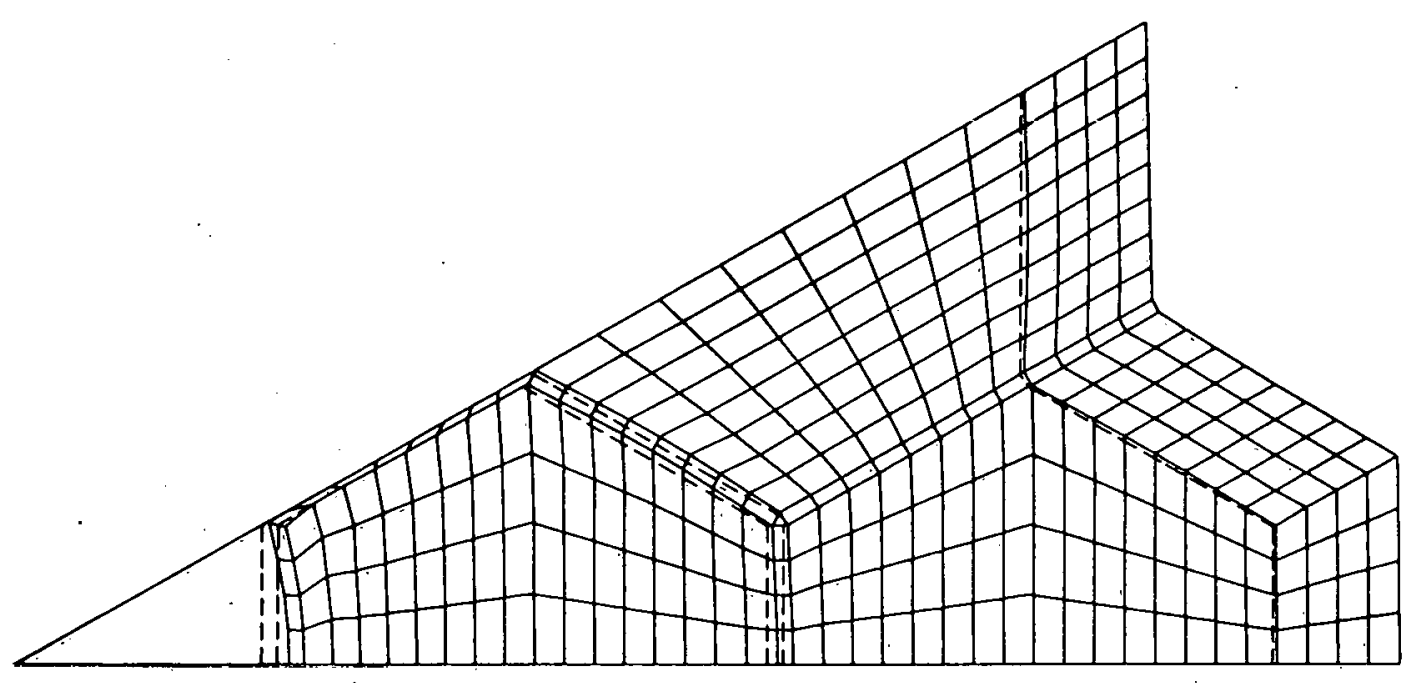

$T I M E=0.25 \mathrm{~ms}$

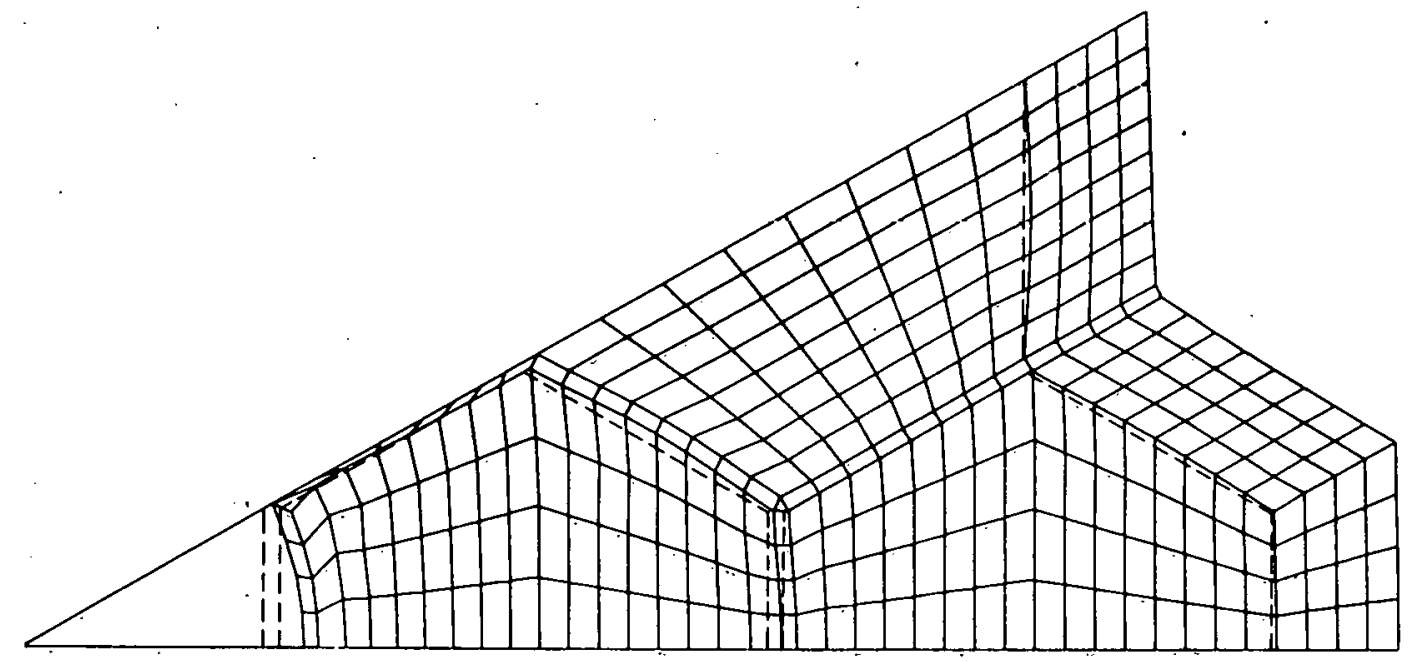

TIME $=0.30 \mathrm{~ms}$

Fig. 26. Deformed Configurations of 2Dt Subassembly CZuster Modez. (ANL Neg. No. 900-78-5.). 


\section{REFERENCES}

1. J. M. Kennedy, Nonlinear Dynamic Response of Reactor-core Subassemblies, ANL-8065 (Jan 1974).

2. N. J. M. Rees, "Mechanical Effects of Core Accidents," International Conference on Engineering of Fast Reactors for Safe and Reliable Operation, Karlsruhe, Germany, Oct 1972.

3. P. H. Denny, N. J. M. Rees, and G. R. Warren, "An Empirical Study of the Effects of a Simulated Sodium Coolant Vapour Explosion in a Subassembly of the PFR Core Sturcture," Paper E 1/7, Second International Conference on Structurai Mechanies in Reactor Technology, Berlin, Sept 1973.

4. R. Krieg, R. Liebe, H. Will, and H. Zehlein, "Mechanical Behavior of the LMFBR Core Structure Under Transient Pressure due to Local Failure," Paper E 2/1, Third Intemational Conference on Structural Mechanics in Reactor Technology, London, Sept 1975.

5. R. Liebe, Subassembly Experiments and a Computer Code to Analyze the Dynomic Core Deformation During Local Failure Propagation, Nuc. Eng. Design, 43, 353-371 (1977).

6. D. S. Rowe, An Improved Mathematical Model for Transient Subchannel Analysis of Rod Bundle Nuclear Fuel Elements, ASME Paper 72-WA/HT-49 (1972).

7. D. J. Cagiiostro and C. M. Romander, Experiments on the Response of Hexagonal Subassembly Ducts to Radial Loads, SRI Report (Dec 1975).

8. C. M. Romander and D. J. Cagliostro, Experiments on the Response of Hexagon Subassembly Duct Clusters to Central Radial Loads, SRI Report (Dec 1976).

9. J. E. Ash and T. J. Marciniak, Comparison of Finite-element Code CalcuZations to Hydrostatically-Zoaded Subassembly Duct Experiments, ANL-77-1 (Jan 1977).

10. J. E. Ash, Comparisons of Finite-element Code Calculations to Dynamicallyloaded Subassembly Duct Experiments, ANL report to be published.

11. D. F. Schoeberle, J. M. Kennedy, and T. B. Belytschko, Implicit Temporal Integration for Long-duration Accidents in a Structural Response Code S'TRAW, ANL-8136 (Oct 1974).

12. A. H. Marchertas and T. B. Belytschko, Nonlinear Finite-element Formulation for Transient Analysis of Three-dimensional Thin Structures, ANL-8104 (June 1974).

13. R. F. Kulak and T. B. Belytschko, An Implicit Three-dimensional Finiteelement Formulation for the Nonlinear Structural Response of Reactor Components, ANL-76-85 (July 1976). 
14. A. H. Marchertas and R. T. Julke, A Computer-code Formulation for Threedimensional Hexcan Response Coupled with Internal Hydrodynamics, ANL-7617 (March 1976).

15. J. C. Bratis and J. Marciniak, "Reactor Structural Response to MoltenFuel-Coolant Interactions," Paper E 1/4, Second International Conference on Structural Mechanics in Reactor Technology, Berlin, Sept 1973.

16. T. B. Belytschko and J. M. Kennedy, A Fluid-Structure Finite EZement Method for the Analysis of Reactor Safety Problems, Nuc. Eng. Design, 38, 71-81 (1976).

17. W. F. Noh, "CEL: A Time-Dependent, Two-Space-Dimensional, Coupled Eulerian-Lagrange Code," Meth. in Computational Physics, Vo1. 3, ed. by B. Alder, Academic Press (1964), pp. 117-179.

18. J. G. Trulio, Theory and Structure of the AFTON Codes, Air Force Weapons Laboratory AFWL-TR-66-19 (June 1966).

19. C. W. Hirt, A. A. Amsden, and J. L. Cook, An Arbitrary Lagrangian-EuZerian Computing Method for all Flow Speeds, J. Computational Phys., 14, 227-253 (1974).

20. J. Donea, P. Fasoli-Stella, and S. Guiliani, "Lagrangian and Eulerian Finite Element Techniques for Transient Fluid-Structure Interaction Problems," Paper B 1/2, Fourth International Conference on Stmuctural Mechanics in Reactor Technology, San Francisco, Aug 1977.

21. O. C. Zienkiewicz, The Finite Element Method in Engineering Science, McGraw Hill Book Co., Inc., London (1971).

22. T Christie, D. F. Griffiths, A. R. Mitche11, and 0. C. Zienkiewicz, Finite Element Methods for Second Order Differential Equations with Significant First Derivatives, Int. J. Num. Meth. Eng., 10, 1389-96 (1976).

23. J. C. Heinrich, P. S. Huyakorn, 0. C. Zienkiewicz, and A. R. Mitchell, An Upwind Finite Element Scheme for Two-Dimensional Convective Transport, Int. J. Num. Meth. Eng., 11, 131-145 (1977).

24. P. J. Roache, Computational Fluid Dynamics, Hermosa Publishers, Albuuerque, N. Mex. (1972).

25. T. Belytschko and B. J. Hsieh, Nonlinear-Transient Finite Element Analysis with Convected Coordinates, Int. J. Num. Meth. Eng., 7, 255-271 (1973).

26. T. Belytschko and B. J. Hsieh, "Nonlinear-Transient Analysis of Shells and Solids of Revolutions by Convected Elements," Proc. AIAA/ASME/SAE 14th Struct., Struct. Dyn. and Materials Conf., Williamsburg, Virginia, March, 1973; J. AIAA 12, 1031-1035 (1974).

27. T. Belytschko and L. Glaum, Higher Order Corotational Formulations for Nonlinoar Fini.te El.ement. Ans.ysis, submitted for publication. L. Glaum, "Direct Iteration and Perturbation Methods for the Analysis of Non-11near Structures", Ph. D. Thesis, University of Illinois at Chicago, 1976. 
28. J. H. Argyris, S. Kelsey, and H. Kamel, "Matrix Methods of Structural. Analysis: A Precis of Recent Developments", Matrix Methods of Stmuetural Analysis, ed. by B. F. deVeubeke, AGARDograph 72, Pergamon Press (1964).

29. T. Belytschko, R. L. Chiapetta, and H. Barte1l, Efficient Large Scale Nonlinear Transient Analysis by Finite Elements, Int. J. Num. Meth. Engr., 10, 579-596 (1976).

30. G. Maenchen and S. Sack, "The Tensor Code," Methods in Computational Physics, Vol. 3, ed. by B. alder et al., Academ1c Press, New York (1964), pp. 181-210.

31. J. M. Kennedy and T. B. Belytschko, Energy Source and Fluid Representation in a Structiral Response Code - STRAW, ANL-8140 (May 1975). 
Distribution for ANL-78-100

Internal:

J. A. Kyger

R. Avery

L. Burris

D. W. Cissel

S. A. Davis

B. R. T. Frost

D. C. Rardin

R. J. Teunis

C. E. Til1

R. S. Zeno

C. E. Dickerman

H. K. Fauske

S. Fistedis

J. F. Marchaterre

H. O. Monson

R. Sevy

A. J. Goldman

I. Bornstein
B. A. Korelc (3)

T. C. Chawla

L. Baker

P. A. Lottes

W. C. Lipinski

D. H. Cho

L. W. Deitrich

D. R. Ferguson

D. Myers (5)

R. A. Noland

A. E. Klickman

J. B. Heineman

J. E. Ash

Y. W. Chang

H. Y. Chu

C. Fiala

J. L. Glazik

J. Gvildys
J. M. Kennedy (32)

R. F. Kulak

A. H. Marchertas

M. T. Abdel-Moneim

H. J. Petroski

H. L. Schreyer

C. Y. Wang

W. Zeuch

A. B. Rothman

A. DeVolpi

R. E. Henry

D. H. Lennox

D. R. Pedersen

J. H. Tessier

A. B. Krisciunas

ANL Contract File

ANL Libraries (5)

TIS Files (6)

Externa1:

DOE-TIC, for distribution per UC-79p (282)

Manager, Chicago Operations Office

Chief, Office of Patent Counsel, $\mathrm{CH}$

Director, Reactor Programs Div., $\mathrm{CH}$

Director, CH-INEL

Director, DOE-RRT (2)

President, Argonne Universities Association

Reactor Analysis and Safety Division Review Committee:

S. Baron, Burns and Roe, Inc.

$\mathrm{J}$. R. Dietrich, Combustion Engineering, Inc.

W. Kerr, U. Michigan

M. Levenson, Electric Power Research Inst.

S. Levy, S. Levy, Inc.

D. Okrent, II, Cali fornia, Los Angeloo

N. C. Rasmussen, Massachusetts Inst. Technology 